\title{
LA LENGUA DE LAS TRIBUS \\ (DE GUÉRET-CHAMINADOUR A SANTA MARÍA DE LOS BUENOS AIRES)
}

Marcel Jouhandeau cuenta como uno de los escritores más curiosos (en los dos sentidos usuales de la voz, y quién sabe si no también en el sanativo) de lo que atañe a la lengua, y quizás como el más apegado a todo aquello que rodeó sus primeros años: "Je tourne sans cesse autour du passé", confiesa en la página 34 del libro que motiva esta pesquisa y en el que se conjugan más ostensiblemente sus dos mayores curiosidades: el volumen quinto de su Mémorial, consagrado a escudriñar Le langage de la tribu recogiendo, de entre sus gentes, "les métaphores entendues seulement là-bas, dans la langue familière de tous les jours":

Parvenu au seuil d'un autre âge, pourquoi ne pas faire le compte de ces vocables périmés qui furent en usage à Guéret. Je les grouperai sans ordre, comme ils se présentent à ma mémoire, mais sous trois chefs:

$1^{\circ}$ Les figures de rhétorique en vogue chez nous. S'il en passe quelques-unes qui ne nous étaient pas exclusivement propres, on me pardonnera.

$2^{\circ}$ Les solécismes, les barbarismes que nous nous permettions.

$3^{\circ}$ Le vocabulaire des mots qu'on ne trouve pas ailleurs et qui étaient d'un usage courant à Chaminadour et dans ses environs ${ }^{1}$.

A estas tres categorías (y dejando a un lado la segunda, exclusivamente francófona) deben agregarse los Proverbes (pp. 95-111) y el material lingüístico esparcido por el resto del libro; vale para

${ }^{1}$ Marcel Jouhandeau, Mémorial, $V$. Le langage de la tribu, NRF-Gallimard, Paris, 1955: el título del volumen es un semi-homenaje funerario de Mallarmé, cuyo verso aludido ("il donne un sens plus pur aux mots de la tribu") tradujo a oreja otro zumbón admirador de Poe ("Poeta es aquél que cura, / dándole sangre más pura, / los males del atributo"). Lo citado viene 
ellos, como para lo precedente, la advertencia de pp. 99-100: remitiendo a una colección de dichos locales, Jouhandeau especifica: 'Mon but n'est pas tout-à-fait le même. C'est le pittoresque de l'expression que je poursuis".

Lo que lo ocupa es, pues, "le Pittoresque lui-même" (Coc. teau dixit), pero dentro de sus límites estrictamente localizados allá lejos y hace tiempo; a "les métaphores entendues seulemen là-bas" y que "tout d'un coup n'eurent plus cours" (p. 63) st unen "des mots qui avaient cours chez nous dans le peuple et qu ne figurent dans aucun dictionnaire officiel" (p. 174). "Là bas", "chez nous", es la localidad de Guéret, que él elevaría : imperio literario bajo el nombre de Chaminadour ${ }^{2}$, y cuyo en canto nos canta: "l'éducation qu'on avait reçue, à peu près 1: même pour tous, du petit au grand", produjo allí "une espèc de miracle: l'unité morale du groupe":

On parlait la même langue... Tout le monde partageait à pe près le même sentiment sur l'essentiel... Pas la moindre infil tration étrangère où, le jeu faussé, tout ce petit monde eût corr mencé à se méfier, à se refermer. Quelle joie et quelle force de n'c voir à faire qu'à des gens que l'on connaît depuis leur enfance. . (pp. 59-60).

Así definido, Chaminadour no parece haber sido muy difє rente de lo que fue el Buenos Aires de mi niñez, cuando dentro di mismo barrio cada barriada guardaba su carácter pueblerino, co su comercio exclusivamente local - "el almacenero" era "don Faustino y daba la "yapa"; ir a la ferretería era "ir a lo de Rezzć nico", y en la peluquería todos comentaban lo de todos-, e tiempos en que "el viaje al Centro" era una expedición, no rie gosa pero sí planeada. Las costumbres eran idénticas:

Le soir, après le travail, comme les moines pour chanter laud. et complies, les commerçants et leurs employés sans distinctior apportant leurs sièges, se réunissaient sur le trottoir autour d'v personnage qui jouait le rôle de coryphée. Les femmes brodant c

de la p. 64; cuando varias citas se siguen, damos la paginación solamente $\mathrm{p}$ ra la primera de ellas.

${ }^{2}$ Guéret, capital del departamento de la Creuse, va denominada $\mathrm{Ch}$ minadour en otras obras de Jouhandeau, que aquí se sirve indiscriminac mente de ambos nombres. 
tricotant, les hommes échangeaient de gais propos ou, selon l'événement du jour, des réflexions graves, quand ils n'organisaient pas sous les yeux des belles qui attribueraient le prix une partie de course à pied ou de saute-mouton.

Una costumbre muy generalizada fue por muchos años la de sacar sillas los tenderos, almaceneros, talabarteros, etc. en las noches de verano, y sentarse en la calle debajo del cordón de la vereda, a fin de no impedir el tránsito de los pedestres; y como tenían la calle por suya, puesto que no había peligro de tranways, carruajes y demás, allí tocaban algunos tranquilamente la guitarra, instrumento favorito, divirtiendo a los transeúntes ${ }^{3}$.

Todavía en los años casi mediados del siglo, en muchas calles recogidas de Buenos Aires los vecinos sacaban sus sillas a la puerta de sus casas y organizaban tertulias, después de la cena, en las primeras horas de la noche, en torno a un personaje de mayor prestigio o simpatía. Incluso las mismas falsas relaciones similares de causas a efectos fisiológicos acentuaban el clima patriarcal de ambas tribus:

Une pauvre femme confuse lui avouait-elle que "son petit" avait des poux, ma mème pour ne pas l' humilier disait: "C'est de l'anémie!' (D'aucuns prétendaient que c'était signe de santé). Ou bien: "Il n'a pas mangé des châtaignes crues?" mi-ironique mi-sérieuse, (le bruit courait chez les paysans que les châtaignes, si on les mangeait, sans les avoir fait cuire, en donnaient), avant de conseiller quelque traitement pratique et un peu d'hygiène (p. 123).

También semi irónicamente, pero otro poco en serio, se afirmaba entre nosotros que ciertos percances de carácter amatorio provenían "de mear contra el viento" o "de tomar mucha cerveza", lo que tampoco excluía tratamientos e higiene. Menos arraigados que en Europa, subsistían algunos prejuicios sobre ciertos rasgos físicos o fisonómicos ${ }^{4}$.

${ }^{3}$ Le langage de la tribu, p. 60. José Antonio Wilde, Buenos Aires desde setenta años atrás, Eudeba, Buenos Aires, 1960, p. 221.

${ }^{4}$ Jouhandeau registra, en p. 97: "femme à barbe / Homme sans barbe, / Prenez garde!". El Diccionario de SBARBi (véase la nota siguiente) consigna: "La mujer barbuda, de lejos la saluda", "Ni a fraile descalzo, ni a hombre callado, ni a mujer barbada, le des posada" y "Guárdate de hombre mal barbado. " (pp. 658, 412 y 483); y en p. 654 se extiende: "A la mujer barbuda, de lejos me la saluda". Algunos añaden: "Con tres piedras, que no con una. 
Esta comunal comunidad organizativa justifica el haber intentado ponderar (examinar, sin encarecerlas) las posibles seme. janzas de la lengua que Jouhandeau evoca con la nuestra, tam. bién común, de entonces. Si bien el mayor aluvión que incide sobre nuestro español básico está constituido por italianismo: - sobre todo en los diversos niveles del habla en la capital-, nc son infrecuentes los préstamos y paralelos con el francés, del "ca. lotear" lunfardo al infantil y lúdrico "vinagre"s. Como Jou handeau (si parva licet, y sin salirnos de la parva) apelamos en pri mer término a la memoria, y podríamos decir con él 'Je n'ai pa la prétention d'être complet, mais je puis affirmer que depui trente ans, à mesure que ma mémoire m'en donne l'occasion j'enrichis ce florilège'” (p. 65). Una elementalísima prudenci nos fuerza el recurrir, sin embargo, a algunos mínimos auxiliare prescindiendo, de una manera general, de las grandes coleccio nes paremiológicas, aquí apenas citadas: exceptuamos, en razó de sus ricas correspondencias, los "Refranes judeo-españoles d Esmirna" recogidos y anotados por Denah Lida. Una referenci. límite proporcionan, en primer lugar, el Diccionario de la Réc Academia Española (decimoctava edición, última que consign frases y refranes), el Gran diccionario de refranes de la lengua español de Sbarbi, y el Diccionario de modismos de la lengua castellana de Ca

Las mujeres que tienen esa condición, suelen tener el carácter hombruno ser, por tanto, amigas de mandar y sopapear al marido": por esta asociació Rafael Alberti hizo salir a escena con barbas a Margarita Xirgu, en su den minado Adefesio. Las prevenciones porteñas son menos arraigadas y pasan $r$ : ramente de burla a condena: al que padece estrabismo le decían que "mis contra el gobierno", y llamaban "cuatro ojos, capitán de los piojos" al q1 llevaba gafas. Un jovial corcovado de mi barrio acostumbraba responder, quien decía "Está muy mal hecho", o simplemente "mal hecho", la muletil "Mal hecho es un jorobado".

${ }^{5}$ Calote, caloteador, calotear han evolucionado desde la aparición de El idr ma del delito de Antonio Delleptane (1894; citamos por la reedición de L Libros del Girasol, Buenos Aires, 1967, p. 79) que los limita a "irse sin p gar": designa hoy cualquier género de robo o estafa. Para "vinagre -opuesto al mucho más calmo "aceite" del salto a la cuerda (en Espai "comba") - Colette, en Mes apprentissages, dice de su doble, rival y amiga P laire: "Je l'avais vue entrer en scène avec une corde à sauter et "faisant naigre»" (citado por Michèle SARDE, en Colette, libre et entrevée, Stock-Éds. c Seuil, Paris, 1984, p. 176). Si por lo general los proverbios y refranes pose correspondencias bastante fieles en ambas vertientes del Pirineo, en algún c so, como en "Comme un chien dans un jeu de quilles" -que perpetúa u: diversión suplantada por la "pétanque" - no conozco equivalente más act tado y previsor que el criollo "como perro en cancha "e bochas". 
ballero Rubio (viejos, pero no desusados), y el muy estimable Dictionnaire français-espagnol de S. Denis y M. Maraval, prácticamente el único en incluir locuciones y refranes. Se entiende que sus aportaciones se limitan a corroborar el uso bonaerense o sirven, menos frecuentemente, para estipular sus diferencias con la lengua general: y, para las expresiones locales, nos respaldará el Diccionario de argentinismos, neologismos y barbarismos de Lisandro Segovia. Otras contribuciones más localizadas se citarán donde corresponda, y más de una vez señalaremos las coincidencias de Jouhandeau con otro texto de carácter regional, La guerre des boutons, de Louis Pergaud 6 .

Lo primero que puede venírsele al lector no prevenido es, a pesar de los repetidos aseguramientos del autor, asombrarse de la cantidad de voces y maneras de decir pretendidamente exclusivas que son comunes a toda la francofonía. En la serie de comparaciones que abren la segunda parte de su libro puede aceptarse que no sea la exclusividad, sino las características de su empleo las que lo mueven a consignarlas:

L'habitude qui avait cours chez nous, c'était de ne se contenter jamais de l'épithète nue... on la faisait suivre d'une comparaison et cette association de mots devenait peu à peu indissoluble... Par exemple, on ne disait jamais adroit simplement, mais: adroit, comme un singe (p. 68).

El hábito local no impide, sin embargo, que locuciones como "pauvre, comme Job" y "riche, comme Crésus" hayan sido acuñadas harto lejos de Chaminadour, de la misma manera que su inclusión por Segovia no da patente exclusiva de porteñismos a

${ }^{6}$ La contribución de Denah Lida apareció en la NRFH, 12 (1958), 1-35; el Diccionario de Sbarbi y el de Ramón CABALlero se citan en las reediciones de Joaquín Gil, Buenos Aires, 1943 y 1947 respectivamente; el Dictionnaire de Denis y Maraval va por la de Hachette, Paris, 1960, y el Diccionario de SEGOVIA por la de Imprenta Coni, Buenos Aires, 1912. A las cuatro primeras autoridades corresponden las siglas Ac. (Real Academia), Sb. (Sbarbi), C. (Caballero Rubio) y D. M. (Denis-Maraval); en el caso de S. (Segovia) agregamos la paginación en razón de las múltiples divisiones temáticas del volumen, donde cada una de ellas posee su propio orden alfabético. La guerre des boutons, en fin, se cita por la reedición de Gallimard, Paris, 1981. Pergaud - como Jouhandeau - rebautiza Longeverne a la comunidad de Landresse, en el departamento de Doubs, y son notables, en dos localidades alejadas e incomunicadas, las voces y locuciones comunes, máxime teniendo en cuenta la diferencia de géneros entre ambos textos. 
las comparaciones con Jeremías (epíteto del llorón, p. 77 qu agrega "jeremiada", y p. 798), Job (imagen de la paciencia pp. 364 y 773), Judas (de nuevo en pp. 77 y 798), y Matusalé (p. 83). La mayoría de los ejemplos de Jouhandeau no sólo reba san Chaminadour sino que se salen del mapa de Francia par instalarse en todo lugar donde se hable su lengua (y bastantes cir culan por las lenguas vecinas), empezando por el que él mism da como ejemplo:

"adroit, comme un singe" (p. 68). D. M. lo recoge s.v. singt

"aimable, comme une porte de prison". Id, s.v. aimable.

"amer, comme fiel ou chicotin". Id., s.u. chicotin, con la corre pondencia "amargo como la tuera"; C. da "amargo como la hiel (fórmula registrada por S. en p. 646), completada por "amargo ce mo tueras" y por "más amargo que el acíbar... que la hiel. . que tueras". Esta última voz, inusitada en el Plata, falta en S., qu da también "más amargo que la hiel" en la misma p. 646.

"beau, comme le jour". La asociación anda por varias expr siones ("un beau jour" 'un buen día', 'el día menos pensado "les beaux jours" 'el buen tiempo', tanto meteorológico como m tafísico), y, como encarecimiento, es usual en los cuentos de had para caracterizar a la hija del rey (y no parece ajena a la vecinda en Darío, de "una tienda hecha del día" y de "tan bonita con tú'”).

"bon, comme du bon pain". D. M., s.v. pain, da "bon comn le pain", forma similar a las que recoge S.: "bueno como un par (pp. 670-671 y 949) y "más bueno que el pan" (p. 777). C. coinı de con Jouhandeau: “bueno como el buen pan", fórmula a la q remiten las cuatro comparaciones siguientes ("como un buen be dito", "como un borrego", "como un cordero", "como un sa to"'); la misma forma adjetivada ("buen pan") en Cervantes, cit do por S., y en la expresión recogida en Esmirna por Denah Li (p. 4, núm. 27, con equivalencias sefardita y peninsular). Tambi se usan en Buenos Aires - pero algo menos- "bueno como 1 pan bendito" y "es un pan de Dios".

"franc, comme l'or..." D. M., s.v. franc y or. La frase figu en el poema de Cocteau Locutions.

"gras, comme un moine" (p. 69). D. M., s.v. moine, con la ، rrespondencia "más gordo que (ou como) un fraile". C. da sı comparaciones zoológico-domésticas (vaca, becerro, cebón, cerc gocho, lechón, ternero) para "'gordo como...", salvo "como condenado" y "un rollo" (seguramente, de manteca); "lechó y "ternero" alternan con "una bola" y "un sabañón" en "n gordo que... "; y el "a fraile gordo, latigazo" de Sb. expresa u 
idea opuesta. Sin embargo, la correspondencia propuesta por D. M. es corriente.

"innocent, comme l'enfant qui vient de naître". La asociación viene desde antes de Herodes pero se perpetúa en la celebración - litúrgica, y más aún popular- del 28 de diciembre, quedando fija en los vocabularios: "Innocent", reza el Vocabulaire de la langue française de Nodier", "se dit des enfants au-dessous de l'âge de sept à huit ans"; y Ac., $5^{\text {a }}$ acepción: "aplícase al niño que no ha llegado a la edad de discreción". Il novissimo $\mathrm{Melzi}{ }^{8}$ registra la asociación en "Gl'Innocenti. Ospizio che raccoglie gl'illegitimi" y en "Innocentino - a, trovatello", valores semánticos perpetuados en la novela homónima de D'Annunzio. C. registra el doble empleo gueretiano (¿gueretense? ¿guereteño?) de la voz: "Inocente como un niño", y también "Como un niño", locución de valor idéntico. He oído además "como un recién nacido".

"joli, comme un coeur". Sobre la ponderación corriente, la lengua aparea las dos voces en "joli coeur" 'barbilindo' y "faire le joli coeur' (D. M., s.v. coeur).

"laid, comme un pou". D. M., s.v. pou, encarece aún más el vulgarismo: "laid comme un pou retourné". El anopluro pervive, en Buenos Aires como en la metrópoli, en las expresiones "piojo resucitado" y "piojoso" 'mezquino', ambas en Ac.

"léger, comme une plume". D. M., s.v. plume; C., "como una pluma" (en el Plata se antepone generalmente "liviano"). La imagen ha invadido las categorías del boxeo: D. M., s.v. poids y en peso, Ac. da los que son límites para los profesionales y los aficionados que caen dentro de esta denominación.

"long, comme un jour sans pain ou comme le Vendredi Saint (parce qu'on jeûnait ce jour-là)'. La primera comparación -la más usual- la da D. M. s.v. long y pain. C., en "más largo que..." y en "ser más largo que..." (pero no en "largo como...',) registra, entre otras varias formas, "Más largo que la Cuaresma" y "que un día sin pan", a más de "Ser más largo que la esperanza de un pobre", aligerada en el Plata en "más largo qu'esperanza 'e pobre" y reemplazada allí a menudo por "más largo que puteada 'e tartamudo'.

"lourd, comme un plomb". Cf. C.: "Pesado como un plomo", "más pesado que un plomo", "ser un plomo", expresiones que connotan todas lentitud tanto como gravitación. Condensadas en "es un plomo", estas locuciones se refieren particularmente a personas u obras poco amenas.

7 Charles Nodier, Vocabulaire de la langue française, extrait du Dictionnaire de l'Académie, Firmin Didot Frères, Paris, 1843.

${ }^{8}$ Il Novissimo Melzi (486 ${ }^{\circ}-490^{\circ}$ migliaio), Vallardi, Milano, 1929. 
"menteur, comme un arracheur de dents". D. M., s.v. arracheu y mentir da, respectivamente, las correspondencias "mentir com" un sacamuelas" y "mentir más que un sacamuelas", reliquias d cuando los odontólogos más o menos improvisados ambulaban d feria en feria alabando sus operaciones y específicos en larga pláticas no siempre verídicas (C.: "habla más que un sacamue las") que corrían pareja con lo cantado por el Dottore Dulcamar en L'elisir d'amore donizettiano. S., p. 281, define "sacamuelas" 'mal dentista' a la vez que 'charlatán'.

"myope, comme une taupe". D. M., s.v. myope, con la exact correspondencia, "ciego como un topo", que falta en C.: de "cc mo un topo" dice caracterizar a "la persona torpe", acercándos más a la tercera que a la segunda acepción - figuradas ambasde Ac. Ésta registra, como C., "burriciego", limitado a "cegatc y extendido por C. a tardo y torpe. Jouhandeau da la expresión s métrica, "sourd comme un pot" "sordo como una tapia' bajo ] forma regional -y latinísima- "Oule et Oulle, nf. (olla), marmit On disait: sourd comme la oulle, nègre (noir) comme le cul de . oulle" (p. 205).

"noir, comme la cheminée ou comme un four". D. M., s. four: "faire noir comme dans un four". El español prefiere "obscul como boca de lobo" (C.: da también "como boca de lobo", y S p. 896) "Como la boca de un horno" (C.: la forma usual en Bu. nos Aires es "como un horno") expresa el calor y no la falta ( claridad. La vinculación de chimenea y negrura fuliginosa persis en la locución burlesca "blanca flor de chimenea", dirigida a l. personas de tez oscura.

"sec, comme l'amadou ou comme un coup de trique". La p1 mera expresión - compárese, en Ac., yesca, segunda acepción fig rada - era usual en Buenos Aires (S., p. 693, "como una yesca" y 946, "seco como una yesca"); el desempleo de la materia 1 arrastrado el de la voz: cerillas y encendedor han reemplazac al yesquero. "Un coup de trique" es el lógico empedernirse c "sec comme une trique" general. Maurice Donnay, en $L$ souvenirs...9", emplea esta última expresión que es el equivalen literal del "seco como un palo" registrado por C.

"simple, comme bonjour". D. M., s.v. bonjour y simple.

"triste, comme un bonnet de nuit". D. M., s.v. triste.

En estas dos páginas (68 y 69) del Mémorial no hay casi nar exclusivamente propio de Guéret: sobre veintiocho locuciones, nos escapan solamente siete (dos, que tratan de Job y Cres se ventilaron antes); y que se nos escapen no entraña en mor

${ }^{9}$ M. Donnay, Des souvenirs..., Fayard, Paris, 1933, p. xi. 
alguno su originalidad sino nuestra incompetencia. Una de las más lóbregas, "paresseux, comme une loche" (p. 69), se torna transparente al restituir sus dos voces extremas: paresseux, en el hablar familiar, no significa 'perezoso' sino 'lento', y loche es vulgarismo por 'limace', y la frase confirma la reputación - merecida, o injusta - de estos gasterópodos, nudistas o conchudos.

Algo semejante, en menos acusado, sucede en las paǵinas siguientes, en las que las expresiones regionales son más numerosas, pero en las que también subsisten voces y modismos de uso más general:

"Planche à pain signifiait maigre" (p. 70). D. M. da, para "cette femme est une table", 'esa mujer es una tabla (de planchar)', especialización de la décimo cuarta acepción académica de tabla: "Parte algo plana de ciertos miembros del cuerpo. Tabla del pecho, del muslo", casi exclusivamente reservada en el Plata para cuestionar, en ciertas mujeres, nuestra condición de mamíferos superiores.

"Bas percé: prodigue". Cf. "bas de laine "gato, trapillo, ahorros" " (D. M.) y, en castellano, "bolsillo roto", "bolsa rota" (C.). Un argentino en París, Marco M. Avellaneda, celebrando a Gómez Carrillo con el brindis que prologa las Romerías de éste, hibridiza "la plata en las medias de lana" 10 .

"Le plat de résistance était le plus substantiel du repas" (p. 71). Es éste, sin dudas, un ejemplo más de la potencia gastronómica de la lengua francesa, que ha impuesto (no hace demasiado) "restaurante" en español, "restaurant" en inglés y el también neologismo italiano "ristorante". (El Diccionario etimológico de Roque Barcia11 da "restaurante" como participio activo de "restaurar", en la acepción no culinaria que este verbo conserva en Ac.; hoy, Ac. añade, a "que restaura", "establecimiento en que se sirven comidas"). "Plato de resistencia" es corriente en el Plata (S., p. 367; "Fig. El que tiene mucho que comer y es de gran nutrición"). Si falta en los vocabularios corrientes, su vigencia ultramarina prueba que no se trata de un localismo gueretiano; recuérdese sin embargo (bien que para $\mathrm{S}$. provenga "del francés plat de résistance") la adjetivación similar, "plato fuerte", del plato principal de una comida.

"J'ai plus besoin d'argent que de conseil invitait à la discrétion les prêcheurs" (p. 73). Oposición tradicional ("les conseilleurs ne sont

10 E. Gómez Carrillo, Rometías, Garnier, Paris, s.f., p. xi.

11 Roque Barcia, Diccionario general etimológico de la lengua española, ed. corr. y aum. por D. Eduardo Echegaray, Impr. de los Hijos de Ricardo Álvarez, Madrid, s.f., 5 ts. 
pas les payeurs: dinero, y no consejos": D. M., s.v. conseilleur, retoma la expresión de Ac.) que viene por lo menos de Séneca ("Pocc sirue dar preceptos si antes no quitan los enbaraços que sirben do daño a su execuçion", lo traduce Mathías Duque"12). Ac. da "Das el consejo y el vencejo", y "Dinero, y no consejos, expr. con qut se reprende a quien da consejos cuando no se le pide, y mucho má: si los da a quien tiene necesidad de dinero", refranes que pasar a $\mathrm{Sb}$. La versión ríoplatense es todavía más expeditiva: "dame (o te pido) plata, y no consejos".

"Pince-lui le nez, il en sortira du lait se disait des béjaunes qui s'é mancipaient trop vite" (pp. 74-75). En Ac.: "Estar uno con l: leche en los labios", y "Tener, o traer...", todas con el mism sentido ("en leche" se dice incluso de los vegetales que no han cua jado todavía).

"N'en pas mener large peignait la crainte" (p. 75). D. M., s.v mener: "ne pas en mener large: no tenerlas todas consigo".

"Les ongles malpropres étaient dits en dueil". D. M. traduc acertadamente "uñas de luto", forma usual en el Plata (S., p. 969 y que no aparece en Ac.; C. morigera ( $i^{O}$ exagera?) en "uñas d alivio de luto".

"Parler pointu, c'était parler comme à Paris, avec préciosité, 1 bouche en culde-poule"' (p. 76). Expresión usual - fuera de Pa ris- para designar diferencias con el uso local (particularmente $f_{c}$ néticas, como en el Sud-Ouest).

"On disait: manger les pissenlits par la racine pour être mort" D. M., s.v. herbe: "manger l'herbe par la racine". Compárese con lo expresiones análogas "comer tierra" (C.), "estar uno comiendc o mascando, tierra", (Ac.).

"Se ronger les sens ou les sangs pour se tourmenter" (p. 77). Sobı que ronger, y se ronger es 'impacientarse, atormentarse' (D. M s.v.), se faire du mauvais sang es, en el castellano de todos los días ( lugares) 'hacerse mala sangre' (D. M., s.v. sang, lo traduce pc "achicharrársele [ou requemarse ou repudrírsele a uno] la sal gre"). Dejando a un lado sens, probablemente fruto de la homofi nía (o cuasi homofonía), la expresión es rica en variantes: a se ro ger, se faire, se suma manger: "Tintin, par derrière, se mangeait lt sangs à les voir ainsi se trémusser et s'agiter" (Pergaud, p. 138 "on se mange les sangs, comme on dit", testimonia Françoise G roud, y Marcel Arland usa "il se mange les sangs" y, como Jor

12 Flores de dichos $y$ hechos sacados de varios y diversos autores por el Doctor $M e$ thias Duque. Lo publica por primera vez Francisco de P. Amat. Impr. de Ant nio López, Valencia, 1917. Es un manuscrito del último tercio del siglo xi (menciona el año 1669); citamos su núm. 24, de p. 96. 
handeau, "t'être rongé les sangs pour deux sous"13. Sb. acumula "achicharrarle, o freírle, o pudrirle, o quemarle a uno la sangre", verbos todos tributarios de Ac., que cumula a su vez "arrebatársele" y "encenderle". C. expide, en "quemarse la sangre", a "quemarse la figura" (con la doble significación de impacientarse y molestarse que tiene en francés el dicho inicial) y da, precedentemente, "quemarle la sangre al lucero del alba". S. apunta (p. 929) "quemarle la sangre a uno", y (p. 646) "amargar la sangre": más usual que esta última forma es "amargarle a uno la vida", que no figura en Ac.

"Faire passer la charrue avant les boeufs..." (p. 77). D. M., s.v. charrue: "mettre la charrue avant les boeufs".

"Dormir en gendarme, pour: ne dormir que d'un ceil". D. M., s.v. gendarme, da exactamente la locución, y la traduce por "dormir como las liebres". Sb. recoge la expresión completa: "Dormir con los ojos abiertos, como las liebres. Dícese de aquellas personas que acostumbran tenerlos a medio cerrar cuando duermen, como sucede a las liebres, por razón de lo sumamente cortos que tienen los párpados. Esta circunstancia hizo creer antiguamente a algunas personas que las liebres dormían con los ojos abiertos, de donde provino seguramente la frase: "El sueño de la liebre», que se aplica a los que fingen o disimulan alguna cosa haciendo como que están dormidos". La frase y su explicación pasan a su Diccionario procedentes de su Florilegio (pp. 161-162, con la variante "acostumbran $a$ tenerlos" y terminando en "... seguramente la frase", referida entonces a la que encabeza el texto). La expresión final agregada ("El sueño de la liebre") sale de Correas, y otras afines registra C.: "Duerme con los ojos [también: "con un ojo"] como las liebres"; y la variante "con un ojo" se comunica a "las lechuzas" y a "los conejos". En el t. 4 (p. 242) de su colección El refranero general español, Sbarbi registra la frase del Quijote (I, xvi): "tener los ojos abiertos como liebre"; la anotación de Clemencín a este pasaje la retoma Rodríguez Marín, en su edición de Clásicos castellanos ${ }^{14}$ amplificándola en su edición póstuma por la mención de Opiano y de Barahona de Soto que da por cierto el caso y lo funda en "el mucho temor que tienen a los cazadores y aun entiendo que a todas las cosas del campo". Agrega Rodríguez Marín una copla de cuna —quizás la más difundida de ellas - y acaba con que "También se dice esto del león, a lo cual se refirió Lope de Vega en su égloga titulada Amarilis: "Con los ojos abiertos el león duerme/y a nadie

${ }^{13}$ Françoise Giroud, Leçons particulières, Fayard, Paris, 1990, p. 116. M. Arland, La consolation du voyageur, Gallimard, Paris, 1963, pp. 33 y 64.

${ }^{14}$ Según Luis Astrana Marín, El libro de los plagios, Biblioteca Ariel, Madrid, s.f., p. 132. 
mata porque a nadie mira" 15 . Su anotación merece varias obse vaciones, en orden inverso: la condición del león se complementí en los seres adversos de los cuentos de hadas (dragón, guardián c un paso riesgoso, etc.) por la facultad contraria: cerrarlos engañc samente mientras vigila, y viene de la mitología clásica y llega Lessing y a Charles Kingsley. La mención de la liebre y su sueñ no es infrecuente en la poesía tradicional española: se lee en ur copla del viejo cancionero de Hurtado (núm. 80, p. 65):

... que no despiertes a mis padres que tienen sueño de liebres.

Lo mismo en la "copla de nana o de cuna" que cita Guichot Sierra en sus Supersticiones andaluzas:
A la nanita, nana, mi niño duerme con los ojitos abiertos como las liebres.

(Es la misma que cita Rodríguez Marín; éste la toma de sus Cant populares españoles y varía "A la ro-ro, mi niño" en el primer ver y regulariza "ojos" en el tercero.) Guichot y Sierra apunta la fra "Tener sueño de liebre" y anota que la superstición figura ent las recogidas por L. Giner Arriban (pseudónimo de Olavarría Huarte), aparecidas en la revista $L a A$ érica $^{16}$. La referencia no infrecuente en la poesía culta: sobre "LXXXII. Porque duermı las liebres los ojos abiertos" (sumario del Lucidario, en BAE, t. 5 p. 81) véase: " $\overline{\mathrm{q}}$ a vuestros ojos abiertos / echas sueño con liebre" (Cota, Amor y viejo, en el Cancionero general de 1511, f. lxx $\mathrm{v}^{\circ}$ ); "Mas yo ¿soy liebre que duermo, / en medio de mis cuidadc / con los dos ojos abiertos?" (Tirso, La Villana de la Sagra, ed. Bla ca de los Ríos, t. 2, p. 167). También fuera de España se cree q las liebres duermen con un solo ojo abierto (cf. Wallace, pp. 12 122 , sobre Catch a weasel asleep) ${ }^{17}$. Y, en fin, no se repara en q Cervantes considera despiertos a sus héroes: "Ya estaba Sane bizmado y acostado, y, aunque procuraba dormir, no lo consen. el dolor de sus costillas; y don Quijote, con el dolor de las suyi tenía los ojos abiertos como liebres", pensando en sus "extrar̃ locuras". Ac. da solamente "Dormir con los ojos abiertos", sin 1 ferencia a las liebres; y la locución que Jouhandeau emplea $\mathrm{p} c$

${ }^{15}$ Quijote, ed. de Francisco Rodríguez Marín, Atlas, Madrid 1947, t. p. 428 , n. a la línea 7.

16 A. Guichot y Sierra, "Supersticiones andaluzas", en Antonio N chado y Álvarez, Biblioteca de tradiciones populares españolas, Francisco Álva y Cía., Sevilla, 1883, t. 1, p. 220, núm. 33.

${ }^{17}$ A. Wallace, Popular Sayings Dissected, T. Fisher Unwin, Lond 1894, pp. 121-122. 
explicar la fórmula usual en Guéret, existe en castellano: "dormir con un ojo" se lee en C. y en S. (p. 746) que agrega: "Dícese de la persona que vive, o duerme, prevemida".

"Se dégrossir: se laver, faire sa toilette". Es reducción del sentido general ('pulirse') del reflexivo dégrossir (D. M., s.v.).

"Faire son beurre, faire sa pelote: s'enrichir de petits profits aux dépens d'un autre" (p. 78). Las dos locuciones en D. M., s.v. beurre y pelote. En beurre traducen "hacer su pelota de dinero": pelota a secas cobra a veces el valor de pella (en su octava acepción académica 'cantidad de dinero'), pero la locución más usual en Buenos Aires, a despecho del calendario austral, es "hacer su agosto".

"Pour exprimer la ressemblance physique: Il lui sort par les yeux: c'est son portrait craché..." (más un vulgarismo más extremado). D. M., s.v. cracher: "être (qqn) tout craché: ser el retrato clavado (ou pintiparado) (de alguien)", en especial de sus progenitores. La expresión más corriente es "ser el vivo retrato" de uno de ellos, y S. recoge (p. 776) "Es la misma cara (o fisonomía) del padre". La locución francesa merece un ligero comentario: aparece ya en el Maistre Pierre Pathelin y su uso literario llega a nuestros días (el Trésor de la langue française da dos ejemplos de su empleo: La joie de vivre de Zola, y Paludes de Gide). Pero es su testimonio inicial el que más comentarios ha originado, y Erik Staff, que agrega el suyo, da una lista de sus predecesores. Maurice L. Radoff reproduce la lista de Staff, incluyéndolo, en su artículo sobre dos expresiones de la farsa de Pathelin y examina, sin inclinarse por ninguno de ellos, los intentos de explicar razonablemente la locución ${ }^{18}$. Su aporte más importante consiste en encuadrar los ejemplos dados por Nyrop de la expresión análoga inglesa to spit (uno de Swift y el otro de Smollet) con uno de 1825 tomado del NED ("A daughter, the very spit of the old captain") y otro muy anterior de Cotgrave (probablemente de la edición original de 1611; su diccionario fue adicionado varias veces de 1632 a 1679 según el catálogo del British Museum): " $\mathrm{C}$ 'estoit luy tout craché. He ressembled him in every part; he was

${ }^{18}$ ErIK STAfF, en sus "Contributions au commentaire de Maistre Pierre Pathelin" (en Studier Modern Sprakveterskap, ut givna av Nyfilasogiska Sällskopet Upsala, Stockholm, 1934, pp. 157-173), enumera los aportes de Gaston Paris ( $R o, 10$ y 30$)$, Nyrop, L. Clédat, Holbrook y Spitzer. Creía yo tener una papeleta con la indicación de una nota ulterior de Spitzer, "Son père tout craché", pero empiezo a creer haberla sonado. El artículo de RADOFF ("Tout craché and cher comme crème") a pareció en $M L N, 53$ (1938), pp. 327-330 (el resto de su estudio, hasta la p. 334, está consagrado a la segunda locución). Paradójicamente, tratándose de una expresión con tanto pedigree filológico, la frase desaparece en el verso 427 de la versión en francés moderno de la farsa publicada por Omer Jodogne, Maître Pierre Patelin, farce du $15^{\dot{\varepsilon}}$ siècle translatée en français moderne..., Éditions Scientifiques, Gand, 1975. 
like him as he had been spit out of his mouth". Podemos, a nuestr: vez, aportar testimonios de otras dos lenguas: el Novissimo Melzi re gistra (s.v. sputato): "Pretto e sputato, 1. fig. Vero e patente; somi gliantissimo"19. Y Correas - para quien la expresión era ya inin teligible- da el curioso empleo de la fórmula en castellano: " $\mathrm{E}$ hijo de la puta, a su padre saca de duda, y a su madre de disput [más una variante de los dos últimos miembros, con madre-dud y padre-disputa]. Porque en adulterinos se tiene opinión que ordi nariamente se parecen al padre; a lo menos las que intervienen a caso afirman que «es suyo escupido", y que «es el padre cortada 1 cabeza""; y: "Escupido. - Para decir que un hijo se parece much a su padre, dicen ansí: "Es escupido su padre"; "Salió escupido : padre»; "Es escupida la madre que la parió»; "como si le escupi ra». Yo creo que se ha depravado la letra de "esculpido" y "escu pir", por "dibujo" y "dibujar de bulto", con sólo faltar la "l»: "escu pir», "escupir»"20. No creo factible imputar todos estos textos influencia francesa, y Radoff ve justo cuando sostiene que debe iI dagarse su origen en la tradición: entre las muchas funciones de saliva (curativa, preservativa, tanto objetiva como mágicament está la de crear un ser a su semejanza o, por lo menos, la de cre: la ilusión de que ese ser existe; uno de los temas de la "huida mág ca",21 es que la hija del brujo o del ser maléfico, para detenerl escupa en el suelo para que durante su ausencia el salivajo la reen place respondiendo por ella a las malintencionadas preguntas $\mathrm{d}$ enemigo. Es también inquietante la existencia del argentinismo $t$ crachar 'retratar' con su declinante descendencia ${ }^{22}$, y que al espu

${ }^{19}$ El Dictionnaire françois et italien mis en lumiere par Antoine Audin. continué par Laurens Ferreti ... achevé, reveu, corrigé, et augmenté... par Sieur Veneroni. . (Tome Second, A Lyon, chez Louis Bruyset, 1707) no I gistra el equivalente en su italiano un tanto cuanto particular: 'c'est le pe tout craché, s'assomiglia del totto al padre hà tutte la fatezza del padre" ( $s$ p. 148 , s.v. cracher y derivados. Nada en el t. 1, s.v. sputtare).

${ }^{20}$ Vocabulario de refranes y frases proverbiales de Gonzalo Correas...., texte é bli, annoté et presenté par Louis Combet, Féret et Fils, Bordeaux, 196 pp. 119 y 629. Modernizamos la grafía.

21 "La huida mágica" ha sido estudiada por AntTi AARne (Die magis Flucht. Eine Märchenstudie, FFC, núm. 92) y por EFraín Morote Best ( Miscelánea Rivet, t. 2, pp. 797-848). Vladimir JA. Propp le dedica el aparta IV del capítulo IX en su libro Les racines historiques du conte merveilleux, NP Gallimard, Paris, 1983 (el original ruso es de 1946), pp. 455-468; no menc na el papel de la saliva.

${ }^{22}$ Dellepiane (cf. n. 5) registra escrachar 'retratar, escribir, anotar'; alfabéticamente, entre escrachador 'fotógrafo' y escracheria 'taller fotográfic voces desusadas hoy. Las sigue escracho 'rostro, fotografía de una persona, c ta', con sus diversos complementos ( $e$. a la gurda, rostro hermoso; e. fulero, $\mathrm{r}$ tro feo; e. volante, careta; hacer un escracho, escribir una carta); la voz ha resbz 
se lo denomine en esas tierras "pollo", antiguamente 'cría de cualquier animal' según Ac.

"Avoir du bien à l'ombre: qu'on disposait de trésors cachés". Cf. D. M.: "á l'ombre: al amparo, al cobijo de..."' (s.v.). En Buenos Aires, como en España, "a la sombra" y "estar a la sombra" significan 'estar en la cárcel'.

"Sentir l'écurie signifiait habituellement grossier de manières et de langage. Appliqué au cheval, tout différent devenait le sens. À l'approche des maisons qui avoisinent la sienne, où l'attendait picotin, boisson fraîche et litière neuve, le cheval s'égaie, son pas devient plus vif, ses oreilles se dressent..." (pp. 78-79). D. M., s.v. écurie, da "avoir des manières (et tenir des propos) diécurie" y "sentir l" écurie, con "aller vers l'écurie", los dos últimos modismos con los mismos dos sentidos que señala Jouhandeau. Para los dos primeros ("avoir..." y "tenir. . .") cf. la expresión - bastante más moderada - "el pelo de la dehesa", teatralizada por Bretón de los Herreros.

"Faire le Jacques s'entendait du mari à qui sa femme impose une besogne peu convenable à son sexe et qui s'y prête"' (p. 79). La frase en D. M., s.v. Jacques, con un sentido algo más amplio - no meramente conyugal- del ridículo. Semejante, pero no igual, es "ser un Juan Lanas" (C.). En p. 798, S. daba entrada, junto a "Es un Juan Lanas", a las locuciones "Es un Juancho (o un Juan Cholongo)", desusadas hace rato.

"Avoir marché sur l'herbe folle: se disait de qui tout d'un coup délirait, déraisonnait, tenait des propos dénués de logique ou de sérieux". D. M., s.v. herbe y marcher: "avoir marché sur quelque mauvaise herbe: haber pisado alguna mala hierba" y "marcher..." con el mismo sentido. En C.: "haber pisado mala hierba", y en Sb.: "Haber pisado una buena o mala hierba" y "Pisar mala hierba", con valor adversativo algo diferente; para otras connotaciones, cf. "Pisó hierba enconada", en mis Textos y contextos.

do, de rostro, a fotografía y a testimonio escrito. El Diccionario manual de americanismos de Marcos A. Morínıgo (Muchnik, Buenos Aires, 1966) deriva del inglés "to scratch" el verbo escrachar, que parece haber perdido sus acepciones anteriores, reemplazadas por 'estropear, ensuciar", con la "Obs[ervación]. Puede ser resultado de un cruce con el italiano schiacciare". Parece tratarse de un efecto de la tendencia general de escracho, que de 'rostro' a secas deriva a 'rostro feo': Morínigo anota sus acepciones "La cara de una persona, sobre todo si es fea. // Esperpento.// Mujer muy fea". De sus viejos matices queda tan sólo "escracho fulero": "ser un escracho" es "ser gran fealdad". Cierto es que la exclamación "¿Qué escracho!" es netamente adversativa (pero incluso "iQué cara!" indica raramente celebración). "Le dio en pleno escracho" no estipula, sin embargo, que el rostro aludido fuera antes forzosamente desagradable. 
"Pour mal coiffé: être coiffé comme un chien fou". ¿Deformación de coiffure à la chien? (D. M., s.v. chien). "A lo perro" califica una forma desgalichada de nadar, agitando los brazos para mantenerse a flote y avanzar, sin coordinarlos con el movimiento de las piernas.

"Ramer les choux: faire quelque chose de stupide (on rame les haricots)". Cf. "s'y entendre comme à ramer les choux: entender de algo como un perro de decir misa", D. M. s.u. ramer 'encañar'.

“Faire ses choux gras de quelque chose: s'en regaler. -De quelqu'un: être fier de le fréquenter, de s'engraisser à ses dépens"' (pp. 79-80). D. M., s.v. chou: "faire ses choux gras: hacer su agosto. . " con idéntica idea de provecho (cf. beurre, supra).

"La poêle se moque du chaudron: se disait quand le railleur aussi était ridicule" (p. 80). Cf. "la poêle se moque du fourgon", D. M., s.v. moquer. Los refranes castellanos van más conformes con la fábula: "Dijo la sartén al cazo..." o "a la caldera..." (Denah Lida registra "La tizna le dize a la caldera: vate más ayá", con quince líneas de correspondencias, p. 16, núm. 156).

"Au lieu de riche, on disait: remuer l'argent à la pelle". D. M., s.v. pelle: "à la pelle: a porrillo", y, s.v. argent, la misma frase de Chaminadour, letra por letra. En Buenos Aires se usa "tener dinero a paladas", forma que falta en Ac., que da sin embargo "apa. lear. Con el complemento directo oro o plata, tenerlo en abundancia". Aún más corriente, en mi tierra, es "tener plata ("dinero", a patadas", expresión esta última ("a patadas") que Ac. acoge "con excesiva abundancia y por todas partes". Con el beneplácitc de Don Alfonso Reyes, hemos leído en rioplatense el verso 84؛ (rapsodia II) de su Ilíada: "de la distante Álibe, donde hay platá a montones"'23. Plata 'dinero en general', tercera acepción del lé xico académico, es la única forma corriente en el Plata - sin per juicio de otras voces que designan la moneda, como "mango" "biyuya", "guita" como en España, etc.-, y por "adinerado' decimos platudo, voz que falta en Ac.

"Au lieu de se vanter: se donner des gants". Literal en D. M. s.v. gant: "darse pisto". Mientras que la locución española "tra tarlo a uno con guante de ante" entraña más precaución que cor tesía, "tratar a uno con guantes" implica en Buenos Aires con sideración, y más si los guantes son blancos (ciertas operacione quirúrgicas en las que el especialista hace notar su habilidad se lla man "de guante blanco", por el guante de lino, puesto sobre el d goma, que debe quedar sin mancha alguna de sangre). Ningun. de estas expresiones figura en Ac.

${ }^{23}$ La Iliada de Homero: traslado de Alfonso Reyes. Primera parte: Aquile agraviado [rapsodias I-IX], F.C.E., México-Buenos Aires, 1951, p. 61. 
"Faire florès: être florissant". Con idéntico sentido ("triunfar, tener éxito") en D. M., s.v. florès. "Florearse", reflexivo, es 'darse pisto', 'atildarse' (dando por segura su propia elegancia); como recíproco, es 'cumplimentarse'; falta en Ac., como andar de florcita, que moteja la excesiva compostura y la presunción que la motiva; también significa 'estar ocioso', lo que se compagina bien con el sentido precedente.

"Faire tapis ou tapisserie se disait des filles qui garnissaient les bancs, autour de la piste du bal et attendaient vainement qu'on les invitât à danser". D. M.: "faire tapisserie: comer pavo, estar de non". Gagini toma de los Venezuelanismos de Rivodó la expresión "comer pavo", y su explicación; "Significa quedarse sin bailar por falta de pareja. Se aplica especialmente a la mujer", en su segunda edición aumentada agrega "Se usa en varios países (Colombia, Méjico, Cuba, etc.). En Honduras «dar capote a una mujer» es no sacarla a bailar" "24. En Buenos Aires (el Diccionario manual de americanismo de Morínigo localiza la expresión en Argentina, Bolivia, Chile, Paraguay, Perú, Puerto Rico y Uruguay) recurrimos también a una tarea doméstica, bien que más familiar y humilde: "planchar. Bailar poco o no bailar una niña en un baile por falta de compañeros que la saquen a bailar" (S., p. 263).

"Etre dans la manche de quelqu'un: pouvoir compter sur sa faveur". D. M., s.v.: "être à (ou dans) la manche de qqn: ser santo de la devoción de alguien". La misma idea de auxilio se da en "Traer una cosa en la manga: tenerla pronta y a la mano" (Ac.); en Buenos Aires es más corriente "sacarse una cosa de la manga", de idéntico sentido pero aplicada en general a recursos no materiales (datos o excusas no previstos por el contrincante). Ambas locuciones parecen aludir a una conocida treta de fulleros.

"Cela me fait bien le gras de la jambe ou una belle jambe pour: Cela importe peu" (p. 81). Literal — salvo "gras"- en D. M., s.v. jambe: "cela me (et le, lui, etc.) fait une belle jambe: para mí (et él, ella, etc.) como si lloviese". "Pierna" designa en Buenos Aires a cada uno de los que participan en un juego de cartas que vaya más allá de la pareja (¿porque son menester para sostenerlo?), y particularmente a aquél a quien le toca jugar en último término (opuesto a mano, que es el que inicia un lance); la frase "es un mozo pierna" alaba habilidad, destreza o astucia.

“'Trouver nez de bois: visiter quelqu'un d'absent ou dont la porte était close". D. M., s.v. bois y visage: "trouver visage de bois: hallar la puerta cerrada"; y s.v. nez: "se casser le nez... fig. encontrar la

${ }^{24}$ Carlos Gagini, Diccionario de barbarismos y provincialismos de Costa Rica, Tipografía Nacional, San José, 1893, p. 146. En su Diccionario de costarriqueñismos (s.l.n.f.: ¿falta la portada del ejemplar consultado? Las Advertencias van fechadas en mayo de 1918), pp. 94-95. 
puerta cerrada". "Darle a uno con la puerta en la narices" es par: Ac. desairarle, negarse a lo que solicita; en Buenos Aires es al pi de la letra la acción de cerrarla bruscamente, dejando fuera a aqué a quien se niega la entrada.

"Faire sa petite bouche: se montrer dédaigneux". D. M., s.z bouche: "faire la petite bouche: hacer el remilgado (ou la remilgada)" Ac. da, s.v. fruncir, "fruncir la boca", y s.v. boca "repulgar uno 1 boca: fruncir los labios", gesto que vale terminantemente en $n$ tierra paro expresar desagrado, si bien no tanto como "torcer gesto", expresión que Ac. recoge en torcer. Fruncir los labios se un generalmente al movimiento de denegar algo: un personaje de $\mathrm{Re}$ Stout "sacudió la cabeza, lentamente, fruncidos los labios..." 25

"Avoir le diable passé par le corps": con precisión de su luge de entrada, pies o hígado ". . f faisait allusion à la possession". L expresión "avoir le diable au corps" — popularizada aún más pc la novela de Radiguet, y más todavía por el film salido de ellaes índice de travesura que puede ser hasta inofensiva, Jouhandea completa, a renglón seguido: "Avoir le diable tout court signifia plutôt avoir de l'esprit'"; para estas últimas acepciones (astuto, o rı voltoso), cf. D. M., s.v. diable, y Ac. "tener el diablo, o los diable en el cuerpo". También usamos "ser la piel del diablo" (Ac.).

" $C$ 'est un prêté pour un rendu, entre gens qui échangeaient jou nellement des services"' (p. 82). D. M., s.v. prêté: "un prêté pour $\imath$ rendu: es pagado en la misma moneda, amor con amor se paga' El modismo español que expresa exactamente la locución france es el que utiliza la Zapatera lorquiana al despedir a su marido aí disfrazado: "Lo comido por lo servido": la edición de Joaqu Forradellas $^{26}$ aporta ejemplos de Correas, el Lazarillo y Vale (Juanita la larga); agréguese "Salir lo comido por lo servido" (C

"Du petit au grand: tout le monde". En D. M., s.v. petit, cr un sentido algo más general (el que evoca Fernández Moreno: “ grande y lo pequeño: / todo para mi verso"). Compárese "chi con grande, sin exceptuar cosa alguna" (Ac.).

"Mettre ses dents se disait des enfants dont les dents commence à pousser". La expresión gueretiana se sirve de un uso particul del verbo mettre, que parecería similar al de la locución mettre $l$ 'parir los animales' (el Dictionnaire de Nodier da como ejemp "cette chienne a mis bas", pero agrega "ce cerf a mis bas" "il s', dépouillé de son bois, son bois est tombé",", con la misma id de segregación). La forma francesa corriente es "faire ses dent

${ }_{25}$ Rex Stout, Muerte de un veraneante, (Death of a Dude, trad. de Maria y Rafael Orta), Molino, Barcelona, 1981, p. 51.

${ }^{26}$ Federico García lorca, La zapatera prodigiosa, ed. de Joaquín For dellas, Almar, Salamanca, 1978, p. 195, n. 424. 
(D. M., s.v. dent). Ac. registra "echar los dientes", s.v. echar, pero no liga, a endentecer, ni el verbo nacer (en animales vello, pelo o pluma; aparecer un astro: acepciones 4 y 6) ni el verbo salir - forma la más usada - que reserva para el sol y los vegetales (acepciones 5 y 6), a pesar de servirse de este último verbo en dientes de leche (acepción 2), y de ambos verbos desdeñados al consignar la expresión "Haberle nacido, o salido a uno los dientes en una parte o haciendo una cosa".

"En avoir pour son argent se disait quand on avait peu déboursé sans doute, mais que l'emplette ne valait rien" (p. 83). Empleo sarcástico - la operación es frecuente en todas las lenguas - de la locución positiva corriente: D. M., s.v. avoir: "en avoir pour... tener por el valor de; il en a eu pour son argent: ha tenido por el valor de su dinero". Agréguese que la fórmula significa - pasando a un plano general- suficientemente', y llega hasta equivaler a "recibió su merecido". Ac. consigna: "Por mi dinero, papa le quiero".

"Au lieu de ressembler à quelqu'un, s'agissait-il d'une égale bassesse morale, on disait: En voilà qui peuvent se donner la main" (pp. 83-84). Cf. D. M., s.v. donner: "se donner la main: darse la mano", y C.: "Darse la mano, metafórica y familiarmente, parecerse una persona o cosa a otra; por lo común, se toma en mal sentido": y éste es el que tiene, en el Plata, "pueden darse la mano" (en Santo Domingo cobra el sentido contrario, 'reñir'). Daniel Granada, en la segunda edición de su Vocabulario rioplatense ${ }^{27}$, registra, con el sentido figurado de "darse la mano", la expresión "se rascan juntos", por "alusión a la costumbre que tienen los animales vacunos y yeguares de rascarse los unos contra los otros", expresión poco o nada usada en mi tiempo, en el que rascarse con alguien indicaba contacto sexual (particularmente si era sostenido: "Fulano se rasca con una negra"').

"Se mettre sur son trente et un: revêtir son plus bel habit" (p. 84). Idéntico en D. M., s.v. trente: "ponerse de veinticinco alfileres". Jouhandeau aplica la locución a su abuelo, venido "inopinément chez nous, à trois heures après-midi, sur son trente et un...", (p. 258). Los traductores de Ruth Rendell afeccionan la locución: "Il savait bien qu'elle se serait mise sur son trente et un pour aller trouver Dougie..." ; "Véra et Jamie, tous deux sur leur trente-etun, avec des vêtements neufs confectionnés par Véra..."; y "Vous êtes fort élégant, lui dit David. Mon père appelait ça "être sur son trente et un". - Mon père disait ça aussi, rencherit Victor. Pourtant il n'avait aucun souvenir d'avoir entendu son père utiliser cette expression", más "Salut, Vie. Je ne vous avais pas recon-

27 Daniel Granada, Vocabulario rioplatense razonado, $2^{\mathrm{a}} \mathrm{ed}$., Imprenta Rural, Montevideo, 1890, p. 215. 
nu tout de suite. Vous êtes drôlement élégant. Vous êtes sur votre trente et un" 28 .

"Les vins de qualité qu'on ne laissait pas dans les fûts, mais que l'on mettait en bouteilles prenaient le nom de vins bouchés. J'entends encore mon père dire..." (p. 85). D. M. recoge la expresión, s.v. bouché: "(vin, cidre) embotellado, -a; de marca", y el héroe de La guerre des boutons describe así los festejos de su padre en las ferias: "il boit sec, des apéritifs, des petits verres, du vin bouché..." (p. 122). El castellano opone débilmente "vino fino", "de marca", a su opósito: "vino atabernado", vendido al por menor (Ac.).

"Mourir d'un coup de sang se disait pour succomber à une attaque d'apoplexie"; y "On mourait d'un coup de sang plutôt que d'une attaque d'apoplexie" (p. 167). D. M., s.v. coup y sang: "congestión, ataque cerebral". S. (p. 340) conserva el galicismo "golpe de sangre. Fig. Derrame que se efectúa en el cerebro, por la roturc súbita de algunos vasos sanguíneos", y agrega "E.", lo que signi. fica "usual en España"; Ac., s.v. 'golpe, consigna únicamente "gol pe de tos".

"Acheter quelque chose pour une bouchée de pain se disait aprè les marchés avantageux. Une acquisition vous ruinait-elle au con traire, on disait: Voilà qui me coûte les yeux de la tête" (pp. 85-86) D. M., s.v. morceau: "acheter qq. chose pour un morceau de pain: com prar algo por un bocado de pan, pagar algo con una limosna"; ? s.v. oeil: "couter les yeux de la tête: costar un sentido"; Cocteau pon la expresión en boca de Somerset Maugham: "Il vient d'achete (les yeux de la tête, me dit-il) deux toiles de Picasso"'29. Ac. da la correspondencias exactas: "He comprado esto por un pedazo d pan", s.v. pedazo, y s.v. ojo: "Costar una cosa los ojos, o un ojc de la cara, fr. fig. y fam. Ser excesivo su precio, o mucho el gast que se ha tenido en ella". Y da también la locución contraria "costar un huevo, m. adv. con que se indica lo barato que cuesta o se venden las cosas". Por obra de la sinonimia "huevo/testícr lo", no registrada en Ac. y ampliamente documentada en , Vocabulario secreto de Cela, suele hoy decirse de lo muy caro: "cue: ta", o "me (le, etc.) ha costado un huevo" (un distinguido acadi mico español propalaba hace tiempo que el régimen imperant había igualado los precios: "Ahora un huevo cuesta un huevo"

${ }^{28}$ Ruth Rendell, Un amour importun [From Doon with Death], trad. pi Gérard de Chergé, Libraire des Champs-Elysées, Paris, 1964, pp. 129-131 Véra va mourir [A Dark-adapted Eye], trad. par Françoise et Guy Casaril, Succ du Livre, s.l., 1988, p. 219; L'homme à la tortue [Live Flesh], trad. par Mich Courtois-Fourcy, Succès du Livre, s.1., 1988, pp. 183 y 270.

${ }^{29}$ Jean Cocteau, Le passé défini. I, 1951-1952. Journal, texte établi annoté par Pierre Chanel, NRF-Gallimard, Paris, 1983, p. 170. 
"Huevo" comparte con "ojo" la expresión que tratamos, en razón de la profunda correspondencia de ojo y genitales: el edicto de Seleuco, la autopunición de Edipo, castigan ambos por do pecado se había; y -alguna vez "por lenguarse la traba"; las más, de propósito- suele decirse "cuesta un güevo de la cara".

"Bouleversé, on disait: Les sangs m'ont tourné..." (p. 86). D. M., s.v. tourner: "toumer le sang (ou les sens) à qqn: revolverle la sangre (o los sentidos) a alguien". Ac. y C. allegan solamente la fórmula afín "revolver el estómago", y Ac. emplea, para las diferentes conmociones de la sangre, los verbos arrebatársele, bajársele (a los talones o zancajos), irsele (id.), encenderle, freirle, quedarse sin ella, subirsele a la cabeza.

' $\hat{E}$ tre toujours par voies et par chemins signifiait qu' on ne savait pas rentrer chez soi". D. M., s.v. voie, da la locución en singular: "être toujours par voie et par chemin"; cf. "Par les rues et par les chemins", trozo inicial de Ibéria de Claude Debussy. C. ensarta "por esas calles de Dios", "por esos andurriales", "por esos mundos de Dios", "por esos trigos de Dios", pero no "por esos caminos", que falta también en Ac. a pesar de ser una de las fórmulas más usuales, idénticamente ampliada en "por esos caminos de Dios" (cf.: "por esos barrizales de Dios... por esos polvillares de Dios...", Lorca, La Zapatera prodigiosa, p. 194 de la edición citada).

"Se moquer du tiers comme du quart: l'indifférence" (p. 87). D. M., s.v. moquer: formulación idéntica, vertida "importársele a uno todo un comino" (léase: "importársele a uno un comino de todo"). En C. se suceden, para importársele, tres pitos, una higa, un ardite, un bledo (también usual en el Plata, que desconoce sin embargo ese vegetal), un comino, un ochavo, un pepino, un pimiento, un pitillo, un pito (quizás la forma más empleada en Buenos Aires), un rábano y un tomilllo; para los numerales gueretianos, recuérdese la fórmula despectiva "del tres al cuarto" (originariamente, al parecer, "de tres a cuarto"). También se emplea, en lugar de "importársele", "dársele", y nás aún "reírse (de una cosa)"; y recuerdo haber oído el ijuegueclllo "me río del Janeiro".

"On appelait "mâle manqué" une fille qui avait trop d'assuranee. Il n'y avait pas l'équivalent pour désigner les garçons qui avaient l'air de filles". D. M. aporta la mitad de la expresión: "c'est un garçon manquê" (s.v. manquê); la otra mitad la da su traducción: "es un marimacho". El eastellano posee las dos expresiones, la que se aplica a muchachas y la dedicada a los hombres, "marica" (y hasta "marimarica"). Y al contrario de lo que ocurre en Guéret, Colette opone joeosamente, en La chatte, "femnielette" a "(h)omelette". En Buenos Aires, como en España, "marica" es harto peyorativo (lo que no es el caso en "marimacho"), y se re- 
emplaza por ' "mujerengo' 'afeminado' (voz que falta en Ac. y e1 el Diccionario manual de americanismos de Morínigo); apelación qu en el extremo opuesto del país (la región de Cuyo) significa exacta mente lo opuesto: mujeriego.

"'Avoir soupé de quelqu'un, de quelque chose: en avoir assez. Ex. On déjeune de mérites, on en a vite soupé (p. 89). D. M., s. souper: "avoir soupé de: estar harto (-a) de". En Buenos Aires se us la frase "verlo (a uno) en la sopa", que tiene el mismo sentido, in dicando simplemente hastío; más extremada es la locución nacid entre los primeros años de este siglo, cuando en las cajas de cerilla aparecían fotografías de diferentes personajes: "Porque para est gente [sus paisanos] no hay duda de que Carolina Otero es un santa mujer llena de collares. ¿Cómo, de lo contrario, habrían d poner su retrato en las cajas de cerillas?" 30 . La práctica dio orige a la frase porteña de desafecto: "No lo puede ver ni en caja 'e fós foros"'.

"Etre d'attaque signifiait qu'on ferait face aux difficultés' D. M.: "être d'attaque: ser de arresto"'. (s.v. attaque). Se dice tambié "de arranque" (G.), y se decía: "tener mucho neque", con valc sustantivo que Ac. no da para esta última voz.

"Meta chin, meta loup. Moitié chien, moitié loup se disait des ger qui laissaient peser sur leurs convictions une équivoque" (pp. 8 ? 90). La asociación - una de las etimologías propuestas para la vc lubricán- es más constante en francés que en castellano, y su us es tanto figurado como literal, aplicándose a la incierta luz crepu cular; la forma más corriente es "entre chien et loup" (Mauri: en $U n$ homme de lettres 31 , la reduce: "moi qui ai toujours eu horre du chien et loup, je cherchais d'une main tâtonnante le commut. teur"'); D. M., s.v. loup, da la forma corriente y la vierte "ent dos luces", expresión que en castellano se aplica a "la hora d lubricán" pero cobra asimismo un valor de situación equívoc aplicándose particularmente al que está borracho a medias pero I del todo.

"On appelait épingles, suivant l'importance du marché, les ce. times, les francs ou les centaines de francs qui entraient dans prix convenu, comme une frange sans importance et que l'ach teur abandonnait, pour le récompenser de sa peine, au garçon c à l'accordeur qui avait conduit l'affaire et permis de conclure (p. 90). Cf. D. M., s.v. épingle: "fig. propina". "Alfileres", "pa alfileres" vale lo mismo en castellano (Ac.).

"Jeter la pierre à quelqu'un: image empruntée à l'Évangile q avait supprimé complètement l'usage du mot propre: médire

${ }^{30}$ Gómez Carrillo, Romerías, p. 150.

31 François Mauriac, Un homme de lettres, Lapina, Paris, 1926, p. 52 
(p. 91). D. M., s.v. pierre; “jeter la à qqn: tirar piedras contra alguien". Ac. da tan sólo "tirar uno piedras... estar loco o muy irritado", reflejo de los tantos cuentecillos antiguos que presentan al enajenado arrojándolas; C., empero, consigna: "Tirar la piedra a alguno. Familiarmente, aludirle; provocarle, por lo común en mal sentido".

"Avoir vu son pompon ou son plumet se substituait à être ivre". D. M. registra ambas expresiones, s.v. pompon y plumet respectivamente. "Vérsele el plumero a uno" es mostrar de qué pie cojea.

"Je lui ferai passer le goût du pain formule courante des menaces de mort". D. M., s.v. pain: "faire passer le goût du pain (à qqn): hacer hincar el pico (a alguien)"'. Otra imagen alimentario-funeral ("Avaler son dernier morceau se disait pour mourir", p. 93) es variante de avaler sa langue y recibe en D. M. idéntica traducción: "(mourir): hincar el pico"' (s.v. avaler).

"Se saigner aux quatre veines se disait quand on se sacrifiait à quelqu'un sans réserve". D. M. da solamente, s.v. "se saigner: sacrificarse". La locución completa es sin embargo usual, tomándose "cuatro" en su acepción extrema de "totalidad": "se saigner aux quatre veines" como imagen del sacrificio es frase que emplean, entre otros, Edmond de Goncourt, Henri Béraud y Jean Giono ${ }^{32}$. Cf. Ac., s.v. sangre: "dar uno la sangre de sus venas".

"Traîner ses guêtres se disait pour voyager pauvrement sans but et traîner la savate pour vivre en clochard"' (p. 92). D. M. da.las dos locuciones: "traîner ses guêtres: callejear" (s.v. guêtre), y "traîner la savate: andar a la cuarta pregunta" (s.v. savate). "Arrastrado" posee en castellano idéntica connotación: Ac. da "pobre, desastrado y azaroso; afligido de privaciones, molestias y trabajos. Luciano trae una vida arrastrada" (cf. "arrastrada", calificación de "vida", en C.) y "pícaro, tunante, bribón".

"Faire des yeux de crapaud mourant d'amour voulait moquer une sentimentalité voyante". Cf. D. M., s.v. faire: "faire de l'oeil" 'guiñarlo', y s.v. oeil: "regarder avec des yeux de poisson frit: mirar con ojos de carnero degollado (ou de carnero a medio morir)". La primera locución (de "mirar" a "degollado"), usualísima, no aparece en las autoridades a mi alcance, y para "ojos de besugo", variante poco usual, Ac. y C. dan sólo el sentido comparativo.

"Ne pas déshabiller Pierre pour habiller Paul signifiait que dans les litiges, les torts étant mitigés, mieux vaut ne pas prendre parti". Salvo la negación inicial, la frase figura en D. M., s.v. déshabiller;

${ }^{32} \mathrm{El}$ texto de Edmond de Goncourt lo cita ANDRÉ BiLly en Les frères Goncourt, Flammarion, Paris, 1954, p. 237; Henri Béraud, La gerbe dior, Les Éditions de France, Paris, 1928, p. 27; JEan Giono, La femme du boulanger, Le bout de la route, Lanceurs de graines, Gallimard, Paris, 1978, p. 240. 
es versión laicizada de "desnudar un santo para vestir a otro (D. M., Ac., Sb.). Jouhandeau da un uso local que no debía se demasiado corriente, si tomamos litige al pie de la letra, y que $\epsilon$ tan sólo una de las aplicaciones del dicho. Denah Lida, (núm. 16; p. 17) recoge otra denominación regional: "Lo quita de Haim, l mete en Bedahaim", agregando siete líneas de equivalencias. $\mathrm{F}$ curiosa la semejanza de la fórmula gueretiana con un dicho inglé: "Robbing Peter to pay Paul"'; la explicación suministrada por s colector, A. Wallace, mueve a desconfiar de racionalizaciones historicismos: en 1550, "several states belonging to Westminst Abbey, which is dedicated to St. Peter, were granted for the repa and sustenance of St. Paul's Cathedral"' (op. cit., p. 56).

"S'être levé du pied gauche, ou le derrière le premier se disait pour e: pliquer ou excuser un accès de mauvaise humeur' (p. 93). D. M s.v. pied, traduce la primera expresión por "haber pisado una ma hierba"; Ac., s.v. pie, consigna "con buen pie", "con mal pie' "con pie derecho", "en buen pie", "entrar con buen pie, o cє el pie derecho, o con pie derecho", "nacer uno de pie, o de pies' pero omite - ¿por superstición?- casi todas las correspondenci levógiras. Para ellas, cf. el ya citado "Pisó hierba enconada".

"Se faire des cheveux signifiait se faire du souci. On avait dû cor mencer par dire: se faire des cheveux blancs". D. M. retoma expresión (s.v. cheveu) y la traduce por "quemarse (ou achicharra se) la sangre". En Buenos Aires he oído con bastante frecuenc la expresión "sacar (a uno) canas verdes" (no figura en Ac.), y " mi niñez creía que lo de "verdes" apuntaba a su color y no a carácter de "anticipadas, tempranas" (una bienhablante españc me asegura que "sólo los negros tienen canas verdes", y está acuerdo en que la expresión, usada en España, denota la inten dad del padecimiento que puede originarlas).

"On disait joliment: - Je suis né aux prunes ou à la floraison, p] tôt qu'en septembre ou en mai"' (p. 94). Cf. D. M., s.v. prui "aux prunes: por (ou en la época de) las ciruelas".

Las correspondencias de los Proverbes (pp. 95-111) son, nat ralmente, mucho más numerosas. Varios figuran literalmente D. M. ("Dans les petits pots, les bons onguents", p. 96; "Brel qui bêle perd sa goulée", id.; "Fontaine, je ne boirai pas de t eau", p. 97, etc.); otros se registran con más o menos ligeras I riantes ("Veut-on du mal à son chien, on le dit enragé", p. c en D. M. "Qui veut noyer son chien l'accuse de la rage"). Ur $\dot{y}$ otros tienen, casi todos, su correspondencia en castellano ( $F$ ejemplo, "Quien a su perro ha de matar, rabia le ha de levé tar'), a veces poco literal: "La force est pour les chevaux, la $r$ 
son pour le monde (l'homme)" (p. 99) expresa lo que "Al buey por el cuerno, al hombre por la palabra", como " $\mathrm{Ni}$ boire ni laisser boire, comme la ronce" (p. 98; alude seguramente al zarzal que rodea una fuente) corresponde a " $\mathrm{El}$ perro del hortelano ni come ni deja comer" (el francés posee, sin embargo, "Le chien du jardinier ne mange pas les choux et n'en laisse pas manger aux autres"). "Plus on remue la fiente, plus elle pue" (p. 98), forma gueretiana de "Plus on remue l'ordure, et plus elle pue" (D. M., s.v. ordure; en remuer agrega, al principio, "Il ne faut point remuer..." y el resto), vale el "peor es menallo" (usual en Buenos Aires, y que D. M. adopta como traducción en ambas entradas); "Tout fait ventre / Qui y entre"' (p. 97): D. M., s.v. ventre, da tan sólo el versecillo inicial y la expresión equivalente "Con las granzas se llena la panza"; más expresiva me parece la frase usual en Buenos Aires: "Lo que no mata engorda". Entre los proverbios, y sin serlo, se entromete la "Formule de serment, prononcée à propos de bottes: Si je mens, que Dieu m'envoie la mort à la minute"' (p. 103). Jouhandeau introduce en su comentario otra locución usual (D. M., s.v. botte: " $a$ propos de bottes: sin venir a cuento...'”); Colette afecciona la fórmula juramental, en una variante que la traslada a otro de los novísimos: "Que je ne voie jamais Dieu si je mens, comme on dit dans mon pays"'33. En Buenos Aires era usual la fórmula confirmativa -imitación del habla orillera - "me caiga muerto": la recoge el poeta Eduardo Jorge Bosco en su Cancionero popular porteño, todavía inédito, piezas 68 y 73 (dos variantes del mismo cantar).

Además de las figuras de retórica, los proverbios y el vocabulario, hay esparcidas por el libro voces y expresiones que se glosan como si fueran exclusivamente regionales y su significado debiera precisarse: "Rendre son tablier"' ('despedirse un empleado doméstico', p. 127), "dent de l'oeil" ("colmillo superior', p. 167), "pays, payse"' ('conterráneo, -a'): todas figuran en D. M., y si Jouhandeau hace preceder la primera por la afirmación 'Ce sont de ces expressions qu'on n'entend plus"' (lo que casa con la extinción de la especie), debe reconocer que la última ya la registraba Furetière (en 1690). Lo mismo llega a suceder

${ }^{33}$ Colette, Le fanal bleu. Reducida a fórmula estricta (sin aclaración "comme on dit dans mon pays" la repite en $L$ 'étoile Vesper y en el acto primero de la teatralización de Chér (OEuvres complètes, Le Fleuron-Flammarion, Paris, $1948-1950$, t. 14 , p. 81 , t. 13 , p. 213 , y t. 15 , p. 21 ). 
con bastantes de las palabras incluidas en el Glossaire (pp. 174 217): “Chanteau, nm., la tourte de pain que l'on n'entamait pa sans tracer dessus avec le couteau un signe de croix" 34 .

Es figura (la parte por el todo) por chanteau de pain, canto cantero del pan (en Buenos Aires la "coca", voz que Ac. recog solamente como aragonesismo por "torta"; los otros trozos era simplemente "pedazos", "rebanadas", "tajadas" o "trozos' nunca "mendrugos" salvo en el pleonasmo literatoide "un mer drugo de pan") $)^{35}$. Louis Pergaud repite la forma complet: “. .. prenez un chanteau de pain... Quand quatre heures sor nèrent, qu'ils eurent filé à la maison prendre le chanteau de pai habituel..." (pp. 24 y 81); Colette usa en cambio "chanteau sin aditamento, de la misma manera que canto prescinde de d terminativo en español: cuando habían terminado de comer 16 monjes, dice Berceo para significar la escasez de lo que venía su mesa, "fincaban pocos cantos", y lo mismo en el refrán "Hi regalada, ¿quieres canto o rebanada?". De uso general sc también “chiâler" 'lloriquear' (p. 186), "chien, chienne" 'av riento, -a’36, “floppée"' 'pila, porrada' (p. 196), “guigner "mirar de reojo' (p. 200), "jugeote" 'entendederas' (p. 201 "'mas" como en español mas 'masía, masada' (p. 203), "quilleı 'sortear antes de empezar un juego' (p. 208; en Buenos Air "contar", aunque las formulillas empleadas rara vez sean pur mente aritméticas), "raffut" 'ruido' (p. 214), "trinquer" "tri car' (p. 215: tercer artículo de Ac., que sólo da 'beber'; vale tar bién por brindar chocando los vasos), voces todas recogidas . D. M. Algunas otras se distinguen de las formas comunes tan s lamente por alguna modificación eventual: "matronière" $p$ "matrone" 'comadrona' (p. 203) o por algún matiz en sus sigr ficados: así la bonita descripción de la

${ }^{34}$ Lo corriente en tierras de España es trazar con un cuchillo el signo la cruz sobre la masa cruda, en el momento de hornearla. Práctica que co pareja con nuestra prevención "no formar cruces" (con los cubiertos so' el plato, por ejemplo).

${ }^{35}$ El pan corriente en Buenos Aires es el "pan francés" ("pan" por tonomasia), cuyos dos extremos aguzados se denominan "coca". $\mathrm{Y}$ "ha pan francés" es repetir estas dos voces en ritmo anapéstico como señal protesta por la demora en un espectáculo: es adaptación del "Rembourse. gálico.

${ }^{36}$ Cf. La guerre des boutons, p. 148: “. . . tu sais qu'on n'est pas chien 1 plus à Longeverne, pas chien de rien, pas même de coups de trique". 
Louée, nf. C'était la foire aux domestiques qui avait lieu au printemps, plus souvent le 24 juin, jour de la Saint-Jean. Ceux et celles qui désiraient qu'on les embauchât étaient parqués dans un endroit déterminé ou se promenaient, nantis d'un insigne qui révélait leur spécialité. Les cuisinières arboraient un bouquet de persil. Les moissonneurs un épi (pp. 201-202).

En D. M., louée es "la plaza donde se ajustan los gañanes" (para la fecha indicada, recuérdese la frase actual "hacer San Juan" y las numerosísimas referencias al hecho de mudarse - de casa, de patrón o de quereres - en refranes y cantares). En "tourteau" 'torta', Jouhandeau regionaliza el término al dar la receta de cómo se lo confecciona en su tierra. Y alguna vez insiste en aclarar una expresión que no lo requiere:

Ce n'est pas de refus, litote pour: j’accepte, tempérait une adhesion enthousiaste (p. 85).

À qui vous offrait quelquechose, pour tempérer l'empressement de l'acceptation, il était d'usage chez nous de répondre par la litote "Ce n'est pas de refus" qui équivalait à "Je ne refuse pas" (p. 164).

D. M. da el correcto equivalente: "No es de despreciar", y JeanPaul Colin registra "ça ne se refuse pas" anotando que "Cette locution est repandue dans le parler familial" 37.

Restan aún bastantes expresiones, aducidas como regionales en Le langage de la tribu, que a pesar de estar lejos de serlo no figuran en D. M.: baste decir que en el Grand Larousse Encyclopédique se encuentran (alguna vez con leves variantes) "savoir ce que parler veut dire", (p. 82), "passer dessus"' (p. 84; el Larousse da: "passer sur" 'pardonner'; cf. en español "pasar por alto"), "c'est du pareil au même"' (p. 83). Mayor interés ofrece cotejar algunas de estas maneras de decir con otras, idénticas o muy semejantes, de la lengua castellana. En primer término se presentan aquéllas basadas en características fisiológicas básicas: equiparar la excreción urinaria con el cuarto elemento celebrado por Borges, dictaminar el carácter o la disposición de alguien por su continente, trasladar a otros reinos de la naturaleza órganos o actitudes sólo propias del hombre. Véase:

37 Jean-Paul Colin, Dictionnaire des difficultés du français, nouvelle édition, Les Usuels du Robert, Paris, 1986, p. 640. 
“Tomber de l'eau, euphémisme pour uriner" (p. 167). La igualaciór de orines y corrientes es corriente (“hacer aguas" 'orinar' en Ac.) Lo pintoresco de la expresión de Guéret se basa en la acepción flu vial del verbo tomber 'desembocar' (en castellano caer apunta indiso lublemente a la lluvia) aplicado a las aguas menores (Ac. y Sb. con fluyen éstas con las otras mayores). Y a mayor picardía sabe 1; frase porteña, exclusivamente masculina: "cambiar el agua a la aceitunas".

“D'une m'as-tu-vu? elle [la madre de Jouhandeau] disait: $O$ est-elle encore allée lever son nez? (p. 128). También en el Plata engrei miento y presunción hallan su asiento en la nariz, con la expresió " "es un nariz parada". Las dos locuciones surgen naturalmente d $\epsilon$ porte de la cabeza, que viene engendrando expresiones similare muy anteriores (si bien anatómicamente posteriores), de megalaujo a cogotudo (Ac., que da las dos acepciones de esta última voz -or gulloso, y nuevo ricacho- no resgistra más que la literal par cuellierguido). La expresión persiste en la novela policial: "C'éta un de ces hôtels incroyablement luxueux, dont la tour dominait d haut les immeubles voisins, tel un nez aristocratique dédeigneuse ment levé",38.

“Baloche, nf. groseille à maquereau. L'arbuste était le balı chier. On donnait familièrement le nom de baloche aux testicules (p. 177). El nombre del aguacate procede de la misma compar: ción.

"Avale-tout-cru se substituait à gourmand"' (p. 129). Entre 1: denominaciones derivadas de tragar (tragaldabas, tragallón, trag; mallas, tragantón, tragón, incluso tragante) la más ajustada a la ( Guéret es el rioplatense "trágalotodo", hermano del "tragas. bles" circense hasta en no figurar en Ac.

"Deux culs qui se sont vus / Pendant cent ans se saluent"' (p. 98). I fórmula "desde lejos se saludan" no es ni inusual ni inequívoc y para indicar una relación de intimidad, se dice en Buenos Aire "Son dos culos en un calzoncillo". Denah Lida (p. 13, núm. 12 registra "Están tu culo, mi braga (están haciéndose zalemas)".

"Tous les chiens me tirent (me déchirent)" aparece, junto a ". donnerais ma vie pour deux sous" como la equivalencia murmurada ; "je m'ennuie" (p. 73). En Buenos Aires, para expresar ese misn decaimiento (por contratiempos económicos, aleatorios, o socialt se usa "estar (o andar) miao ['meado'] por los perros".

${ }^{38}$ Paul Mazon traduce el $\mu \epsilon \gamma \alpha \lambda \alpha u ́ x \omega \nu$ de Los Persas como "altier (Eschyle, Les Belles Lettres, Paris, 1969, t. 1, p. 81); véase la familia de e: voz en el diccionario griego de Bailly. William Irish, Lady Fantôme [no lle título original ni se da el nombre del traductor], Les Classiques du Crin Genève, s.f., p. 129. 
Ciertas acciones o situaciones se motejan, en Guéret y en Buenos Aires, con expresiones distintas pero de común denominador:

"Introduire ses doigts dans son nez: c'était nettoyer ses écuries" (p. 75). La operación - a pesar de sus fines, poco higiénica: Paul Léautaud escribe que evitaba dar la mano a uno de sus adeptos- se denomina en Buenos Aires "mudarse" ("Fulanito va a mudarse, o se está mudando"), término aclarado por la imagen complementaria, que precisa: "Está descolgando los cuadros".

"Etre l'officier payeur se disait de celui qui faisait les frais d'une affaire ou d'une fête, sans participer aux bénéfices ou aux divertissements" (p. 82). Es en el Plata "ser el pato de la boda" (S., p. 951), seguro cruce de la expresión española "ser la vaca de la boda" con la también general, pero más localizada "pagar el pato" (véase, para esta última, Daniel Granada, loe. cit., pp. 216-217).

"N'avoir pas coupé la patte à coco ou inventé le fil à couper le beurre se trouvaient sur les lèvres de tout le monde" (p. 93). Es lo que "no haber inventado la pólvora" o "ser el que asó la manteca" (ambas expresiones en Ac.).

Una misma voz, salida de un étimo común, deriva, en nuestros dos lugares, a acepciones si no opuestas, distintas:

"Cabiole, nf., cage, tonnelle, endroit couvert où dans les jardins on rangeait l'arrosoir, la pelle et le râteau (autres formes: gabiole, jabiole, dérivés de geôle)" (p. 183). Compárese con el vascuence cayola y con el andalucismo gayola. En Buenos Aires la voz gayola - y rehilada- ha perdido su primera acepción académica, 'jaula', y conserva únicamente la segunda, 'cárcel', voz que aparece al hablante como una creación semántica (e incluso fonética) netamente lunfarda, y no (para traducir a Olavo Bilac) como "hija última del Lacio" (cf. geôle, gaol, jail).

Y a veces una expresión compleja, similar o hasta idéntica, llega a albergar significados totalmente distintos:

“Avoir le sang à l'oeil: être en bonne santé (au propre). Réussir, faire de bonnes affaires (au figuré). Mettre le sang à l'oeil de quelqu'un: se disait d'un bénéfice ou d'une aide qui le renflouait' (p. 81). La expresión castellana literal, burlada por Quevedo en la dedicatoria del Cuento de cuentos ("Y el blasón tan presumido de tener sangre en el ojo, más denota almorranas que honra") va derivando, de un valor netamente positivo y noble, el único que dan los viejos reperto- 
rios, a uno de más o menos perfunctoria alevosía. Ac. recogía la primera, s.v. sangre: "en el ojo. fig. Honra y valor para cumplir las obligaciones. U. m. con el verbo tener" (prácticamente lo mismo en C., en sangre en el ojo). Llevada por el uso, Ac. ha agregado una segunda acepción: "Resentimiento, deseos de venganza", única - con cambios de verbo- usual en el Plata: "Andar con sangre en el ojo", en S., p. 650; "sangre en el ojo" en p. 945 (donde da como ejemplos "estar con sangre en el ojo" junto a "tener...'); y p. 971, donde repite esta última expresión, más como testimonic de fidelidad a Ac. que como indicio de uso más frecuente. ¿Lubricación motivada por el acendrado concepto del honor, cuya primera exigencia es la puntillosa reparación? En todo caso, el sentidc más reciente no desdice de "con los ojos inyectados de sangre" signo de ferocidad.

Sucede también que, con total identidad de sentido, la expre sión adopte, en las dos lenguas, formulaciones diferentes, adap tándose a las contingencias locales:

"Avoir du sang de navet se disait des pâles et des lâches" (p. 82) D. M., s.v. sang, reproduce la expresión y produce "tener sangr de horchata" (se da también, en francés, "avoir du jus de pru neaux dans les veines", y Pergaud pone en boca de su héroe 1 . exhortación ". . .vaut mieux avouer qu'on a de la purée de pom mes de terre dans les veines et pas du sang rouge, du sang fran çais...", p. 116). Ac. da, con el mismo valor de "calmoso, qu no se altera por nada' (con la debilidad y la cobardía se conjug acertadamente la prudencia), la expresión producida por D. M. aunándola con "No tener sangre en las venas" (en D. M., tan: bién s.v. sang, aparece la forma afirmativa: "avoir du sang dans le veines") y "Tener de chinches la sangre". La primera (". . ho1 chata") es, con perdón de la rima, la usual en el Plata: la da S p. 373 y p. 141, donde apunta el análogo portugués, similar al últ mo de los tres citados en Ac.: "sangre de barata (cucaracha)".

La misma fluctuación se da en "finir en eau de boudin: volvers agua de cerrajas" (D. M., s.v. eau). Ac. acumula "agua de cerrć jas", "Convertirse una cosa en...", "Hacerse...,", "Volve: se...", y "agua de borrajas", con remisión a la de cerrajas. Agr de borrajas es la forma exclusivamente empleada en el Plata, dor de ignoramos qué sean cerrajas (S., pp. 636, 924 y 994; C. c "agua de cerrajas", "aguachirle" y "agua en cerrajas", que lo escurridizo e inseguro). "Convertirse..." y "Volverse... van en $\mathrm{Sb}$., que agrega otra comparación del mismo géner 
"Parece agua de castañas", por el chocolate claro; en Buenos Aires se dice, del café excesivamente aguado, o malo por otras razones, que es "jugo de paraguas".

Curiosas son aquelllas expresiones en las que idéntico sentido parece servirse da traducciones literales que no caen de sí: a los ejemplos ya recogidos pueden agregarse los siguientes:

"Si le sexe des enfants se montrait, on leur enjoignait de fermer leur boutique" (p. 78). En Buenos Aires se dice, a cualquiera que vaya desbraguetado, "Tenés la botica abierta", añadiéndose, si llega a jugar la organografía "y al boticario en la puerta". Es singular la coincidencia entre estas advertencias tradicionales, que por lo general suelen diferir muy variadamente. Inmediatamente antes que ésta, Jouhandeau recoge "Quand, la braguette mal boutonnée, votre pan de chemise apparaissait: la nappe est mise, disait-on, pour vous inviter discrètement à réparer ce désordre". Casi igualmente discreta es la advertencia bonaerense "Te mordió el perro" de una ciudadana a otra cuya falda - más bien dicho: "pollera" - ha quedado englutida o entregluteada; el equivalente antiguo de "la nappe est mise" es mucho más caridelantero que caritativo: "Otro anda con tu mujer. Dícenlo al que se le quiebra la agujeta de las bragas": así en Correas.

"La moitié du monde se moque de l'autre: suggérait que le ridicule est partout et aussi l'esprit de dénigrement" (p. 80). D. M. (s.v. monde) da tan sólo "se moquer du monde: burlarse de la gente (ou del mundo)"; simétrica insuficiencia es la de Ac., con sólo "medio mundo", de valor cuantitativo inferior pero similar al de "todo el mundo", que también recoge. Sb. registra "Medio mundo trata de engañar al otro medio". Sin embargo, la locución usada en Guéret es un viejo refrán empleado por Baltasar Gracián en su Oráculo manual: "la mitad del mundo se está riendo de la otra mitad..." y corriente en el Plata: "Medio mundo se ríe del otro", o "del otro medio" 39 .

"Ne pas cracher dessus: litote, pour aimer (en parlant d'un mets)" (p. 84); falta en D. M., s.v. cracher. En Ac.: "No escupir uno una cosa. fr. fig. y fam. Ser aficionado a ella". C. sólo aporta la variante positiva (que es, en realidad, negativa): "Escupir una cosa. Metafórica y familiarmente, recharzarla; despreciarla". Compárese con la expresión rioplatense, también estrictamente

39 Oráculo . ., aforismo 101, p. 190 de la ed. de Romera Navarro; cf. BHi, 59 (1957), p. 329. Torner, en su Lírica hispánica (núm. 147, p. 247) registra "Medio mundo se ríe / del otro medio..." como fragmento de cantarcillo. 
culinaria: "Escupirle (a uno) el asado", usada con complementc indirecto o sin él, donde el "plato de resistencia" local alude a ur negocio o asunto importante que se trata de hacer fracasar.

"Chauffer les bancs signifrait: faire antichambre" (p. 87). Lo modismos españoles que utilizan la voz asiento - más general qu banco- giran en torno a la primera acepción de la voz en Ac., a la décimosexta, figurada ('permanencia'); descartados estos últi mos, quedan en el diccionario el que equivale por su sentido a 1 forma usual en Guéret ("pegársele a uno el asiento, o la silla" y el que, aunque de sentido contrario, adopta la misma imagen la misma voz - que aquél: "No calentar uno el asiento". Lo regis tra también C. acompañado de "No calentar el puesto, aquell. que dura poco en un sitio", expresión que falta en Ac.; tambié es, por su sentido, negativa la expresión "culo de mal asiento' (Ac.). "Calentar el asiento" 'aguardar' es forma nada inusitad en el Plata.

"Avoir des mots avec quelqu'un, pour disputer". Cf. Ac.: "Tene palabras, fig. decirse dos o más personas palabras desagradables" La forma más usual en el Plata agrega el artículo indeterminadc "Tuve unas palabras con Fulano".

"Ma mère disait plus volontiers toute la sainte joumée, ce qui er noblissait le temps"' (pp. 132-133). Cf. la acepción décimonona d santo en Ac: "Con ciertos nombres encarece el significado de é: tos", y como ejemplo, tras "su santa voluntad", "el santo suelo" da "esperó todo el santo día"; y s.v. día: "Todo el santo día. lor adv. fam. que se emplea para expresar con exageración todo , tiempo de un día'. La locución es usualísima en todas partes.

' 'Je te connais, comme si je t'avais fait, boutade qui n'avait pas tor à fait le même sel, selon qu'elle s'adressait à un autre ou à moi (Mots de mon père, p. 151). C. va extremando: de "Le conozco com si fuera hijo mío" y "Le conozco como si le hubiera parido" (fo: ma la más usual en el Plata — con "lo" y no "le") llega a "Le cr nozco más que la madre que le parió”.

"Il y avait, prétendait-on, un dieu pour les ivrognes et les somnan bules, - qui les empêchait de tomber ou les préservait de faire de chutes mortelles" (p. 94). "Tener un Dios aparte" se dice en Plata particularmente de los niños, que suelen salir ilesos de $k$ riesgos que afrontan; pero asimismo se aplica a los adultos ( $\mathrm{S}$ pp. 971 y 973). También suele decirse que tal catástrofe o hech adverso no ocurrieron "porque Dios es grande". Confieso habe creído, en mi primera infancia, que "grande" se refería, no a s misericordia, sino a su divina condición de ya mayor, que le pe mitía realizar hazañas vedadas a los que no éramos adultos; emp ro Ac., que recoge "Dios es grande", recoge también "No es Dic viejo" y "No se ha muerto Dios de viejo". 
Más curiosas aún son ciertas similitudes a primera vista inexplicables, residentes en elementos no esenciales de la locución que permanecen constantes mientras los términos fundamentales son sustituidos por otros: así "gentil" en

"Sortir en gentil cou se disait pour aller en taille, sans manteau" (p. 70); Jouhandeau emplea, para aclarar la expresión local, el modismo corriente, "sortir en taille". La expresión española (y americana) general correspondiente es "andar en cuerpo", condicionada - negativamente - por cada lexicógrafo con las prendas más familiares para él: "Andar vestido; pero sin abrigo exterior, como el sobretodo, tapado, etc." (S., p. 651, que agrega "Andar en cuerpo de camisa", forma reemplazada en mis tiempos por "andar en mangas de camisa"; Ac. da las dos formas y prefiere mangas, que admite el porte del chaleco). C., a diferencia de Ac., toma la locución en andar y no en cuerpo: y el sobretodo y tapado de S. son para él capa y mantón; Ac. transmite a los citados lo de "abrigo exterior", pero, antifeminista hasta hace no mucho, registra sólo "Sin capa, gabán ni otro abrigo exterior". Una forma más extremada, común a España y a América, es "Salir a cuerpo gentil" (o: andar, en cuerpo gentil), en la que el adjetivo oscila entre 'gracioso' (irómeamente, pues por lo general se reprueba esa imprudencia) y 'notable' (que vale por reprobado).

Hay todavía coincidencias más sorprendentes. Entre las oraciones fúnebres más o menos despiadadas, Jouhandeau recoge: "en voilà un qui ne valait pas son cul plein d'eau chaude" (p. 75). Ac. da la expresión clásica "no valer uno sus orejas llenas de agua. fr. fig. y fam. Ser muy despreciable", que repite textualmente $\mathrm{Sb}$. y que $\mathrm{C}$. omite entre sus encomios de minusvalía (si vale el oxímoron). La inesperada correspondencia de las dos inesperadas expresiones es notable, pero quizás el más sorprendente de los modismos gueretianos sea “Battre l'eau dans l'expression: "Je peux lui demander de battre l'eau" s'employait pour peindre une personne prête à vous rendre tous les services, au doigt et à l'œil, même les plus vains et sans réfléchir"' (p. 70). Cierto es que en francés existe la locución "battre l'eau avec un bâton: machacar en hierro frío" (D. M., s.v. eau), pero - sobre lo adversativo de su significado - no impide el insistente recuerdo de la debatida expresión paralela "bailar el agua". Dejando a un lado a los costumbristas del siglo pasado, dos de los estudiosos que la han tratado últimamente aportan sobre ella informaciones complementarias. Gillet, en su monumental edición de Torres Naharro, 
parte del verso 40, en el acto segundo de su Comedia Seraphinc (verso final de un parlamento de Dorosia): "bailar el aigua de. vant', ilustrándolo con el Diccionari catalán de Labernia y Este ller y la Fraseología de Cejador, y citando con el Lazarillo de Lunc a Polo de Medina, Pedro Espinosa, Quevedo (y su réplica en e Semanario erudito), Quiñones de Benavente, Cervantes (el Quijote por la edición de Rodríguez Marín en Clásicos castellanos) y el $\mathrm{Li}$ bro de refranes de Pedro Vallés; de los textos antiguos da solamen te, in extenso los de Luna y Polo de Medina, y agrega, con Ceja dor, el de la Comedia Florinea que difiere de los demás al dar sólc "bailar delante" (sin agua). No advierte, sin embargo, que To rres Naharro concuerda con Vallés, y que la expresión estudiad: comienza en el verso precedente: “ . . . que’m fa (com és mester) ballar el aigua devant'. Rodríguez Marín, aunque titule Baila el agua el Apéndice XXV de su edición póstuma del Quijote ${ }^{40}$, sı inclina por la forma más larga ("...delante"), y a las autorida des comunes con Gillet (Quevedo, prólogo y texto del Cuento d cuentos $^{41}$, Quiñones de Benavento, Vallés, Cervantes) agrega li rectificación a Covarrubias (equivocado en Cejador: no es él sinı su editor, el P. Noydens, quien menciona la frase), más la cit: de fray Luis de Granada en el Diccionario de Autoridades, las dife rentes versiones de tres traductores antiguos del Quijote, las Elt gías... de Juan de Castellanos, la Agricultura del P. Pineda, lo Discursos predicables de fray Juan de Tolosa, un romance de Que vedo $^{42}$ y sus propias notas al Casamiento engañoso y coloquio de lo perros. (A las autoridades aducidas puede agregarse el Entremés a los refranes y la Guía y avisos de Liñán y Verdugo ${ }^{43}$ : ambos adop tan la forma "bailar el agua" con agua a secas.) Opina Rodri guez Marín que la frase significa "salir al encuentro [del agasaja do] para dársela, echándola a su presencia, bailándola en el vasc de la jarra o alcarraza donde estaba puesta a enfriar' y da la variantes de la locución en pueblos de Sevilla y de Granad ("bailar el agua de nieve") y la cordobesa de Priego, ya impres en Los 6.666 refranes de mi última rebusca ${ }^{44}$ con un recuerdo a $\mathrm{s}$ amigo y colector: "A la gente rica, todos le bailan la jarrica":

${ }^{40}$ Atlas, Madrid, 1949, t. 10, pp. 18-21.

${ }^{41}$ Obras festivas, en Clásicos castellanos, pp. 170, 183 y 187.

42 Es el núm. 785, p. 1075 de la $1^{\text {a }}$ ed. de Blecua.

${ }^{43}$ Entremés de los refranes, en Cotarelo 179 b; y en la reedición de 1s Cuatro entremeses atribuidos a Miguel de Cervantes de Adolfo de Castro (Barcel na, 1957), p. 148. LiÑán y VERdugo, p. 127 de la edición académica.

${ }^{44}$ C. Bermejo, Impresor, Madrid, 1934, p. 177. 
Su explicación aparece como más ajustada que la de Noydens en el Tesoro de Covarrubias, que pasa más o menos invariada a Clemencín, a Seijas (que cita juntos a Covarrubias y a Clemencín en la p. 18 del t. 8 de la colección de Sbarbi, sobre el Cuento de cuentos), al Diccionario de Sbarbi y a Bastús. Las diferentes autoridades se inclinan ya por una, ya por la otra forma del dicho, y - lo que abunda no daña - hasta por más de una: si Musso y Fontes consigna sólo "Bailar el agua: esmerarse en agradar", Correas, como Quevedo, da "bailar el agua delante" y "haber bailado el agua delante", y Ac. opone "bailar uno el agua a otro" y "bailar uno el agua delante a otro". Rodríguez Marín desecha, al parecer equivocadamente, la versión seca de Castellanos en sus Elegías de varones ilustres de Indias ("bailándolos estábamos delante") apostillándola: "Como se echa de ver, no le cupo el agua en el verso". No recordaba - debía conocerlo- el pasaje similar de la Comedia Florinea, e ignoraba seguramente su no esperada perpetuación rioplatense en el Organito de Armando Discépolo: "Saverio: . . La gente quiere olvidarse que sufre. Hay que bailarle adelante, hacerla reir, darle alegría, bombo, platillo, cascabele" ${ }^{45}$.

Puede temerse que toda esta constelación de aproximaciones o identidades dé una imagen errónea del vocabulario de Jouhandeau (de Guéret). Hay en Le langage de la tribu cantidad de creaciones expresivas que por lo menos yo no sabría equiparar con expresiones similares de otros sitios; pero entreverada con ellas aparece una cantidad no menos respetable de fórmulas propias de ámbitos menos locales. Procediendo de menor a mayor, un primer círculo muestra que la lengua de Guéret forma parte de la francofonía. A esta perogrullada cabe añadir otra: toda encuesta sobre un habla local es inseparable de la lengua general correspondiente, y su colector no puede en manera alguna prescindir de las formas comunes a ambas: su tino consiste esencialmente en satisfacer a cada uno de los dos Césares. Como se ha mostrado - y como es segurísimo que podría seguirse mostrando-, el proceder de Jouhandeau, más sentimental que filológi-

45" "Cascabele", sic (texto en Ordaz, Siete..., p. 202). Si la expresión española está más o menos fijada (" . . en vez de escribirle un prólogo bailándole el agua, alabándole el gusto, sin pizca de sinceridad...", Clarín, pról. a Almas y cerebros de Gómez Carrillo, Garnier, Paris, s.f., p. x), en América Central la reemplazan curiosas variantes: "bailarle la caravana a uno" (GAGINI, pp. 82 y 67-68 de sus dos ediciones: remite a caravana en Ac.; MAlareT, p. 408), "sacar la jícara" (de chocolate: GaGini, pp. 539 y 218). 
co, no separa con claridad los dos ámbitos, y registra como propias expresiones que son notoriamente comunes. Un círculo algc - bastante- mayor abarca el legado de una evolución cultura que desborda los límites de la lengua, abrazando creencias ) costumbres que la lengua impone pero que la sobrepasan: Job "jeter la pierre", se sobreponen a las circunstancias locales:

Chaque dimanche mon grand-père en grand tralala $\downarrow$... n'hésitait pas à faire deux kilomètres aller et retour pour entendr la messe à laquelle il assistait, seul de son sexe. A cette époque el effet, à Chaminadour, un anticléricalisme si farouche, si véhémen sévissait que, soit mépris, soit respect humain, aucun homme $n$ mettait les pieds à l'église. Même les jours d'enterrement, avec us mauvais goût, une affectation insolente qui brimait jusqu'au moı et à la famille qu'ils se devaient d'accompagner dans son chagrin "nos Messieurs" se faisaient un point d'honneur de s'égailler dan les cafés durant les Libera et de ne reprende le convoi qu'à la sorti de l'office qui ne les intéressait pas (pp. 236-237).

De la misma manera, Enríquez Gómez, que pagó con su vida 1 fidelidad a la religión de sus mayores, no puede sustraerse a mer tar - siquiera por boca de sus personajes- expresiones tomadz de los evangelios de San Mateo y de San Juan ${ }^{46}$. Sin excesiv escrúpulo, pueden colocarse en este ámbito el recuerdo de Cres y hasta las implicaciones de la honestidad vestimentaria o $\mathrm{h}$ giénica.

De una convención generalizada (negro igual duelo, y de al su afectación a las uñas) podemos resbalar a comparaciones má elementales, más generales, como la de las aguas. En todos estr ámbitos juegan, como es fatal, fuerzas que no son puramente liı güísticas, aunque se expresen verbalmente: "Ma mère disa volontiers: c'est joliment beau comme c'est joliment laid, où jol ment perdait son sens propre", (p. 170). Tal "pérdida de sent do" no es en nada particular: un centenar de páginas antes, nos dice que "Faire joli se disait familièremente pour se fâche «En rentrant, il a fait joli» (p. 85). El empleo irónico de joli ejemplifica dos veces en el Dictionnaire de Nodier, y en lindo A remite al peyorativo "linda pieza" (en realidad los peyorativ

46 Antonio Enríquez Gómez, El Siglo pitagórico y Vida de don Gregorio Gi daña, pp. 230 y 210 de la ed. de Charles Amiel, Ediciones Hispanoameri nas, Paris, 1977. Cf. BHi, 84 (1982), 205-206. 
se acumulan, en la entrada "buena, gentil o linda pieza") 47 . Pero el encarecimiento puede perder su carácter irónico y tornarse decidida, neutramente aumentativo: "un buen par de semanas" no significa que éstas hayan sido buenas o malas, sino que su transcurso (sobre todo en espera de algo) ha sido largo; el inglés usa corrientemente, como la madre de Jouhandeau, "awfully nice", y el sapiente Camus de Pergaud repite la figura: "-C'est salement bien! jugea Camus, exprimant ainsi le summum de l'admiration", y "c'est salement bon!' (pp. 168 y 212); idéntica equipolencia preside el empleo popular de "excessivement" ("excessivement bon") en el sentido de "extremadamente"; estos contubernios son un ejemplo de la atracción de los contrarios, ya advertida por Aulo Gelio ${ }^{48}$ y estudiada por Freud (sus expositores la traducen por "polaridad") y que ha hecho que "lívido" se tome generalmente por 'pálido, demudado', y que "seno" signifique a la vez cavidad y protuberancia. La lengua de Guéret alberga comparaciones obligadas, por no decir fatales: hiel y amargura, pan y bondad; éstas son "de cajón", como dicen Ac. y los porteños. Algo más allá se colocan asociaciones que resultan de una experiencia cultural algo más avanzada, fruto de costumbres y usanzas: en soupé la sopa, el alimento más repetido, engendra la idea de reiteración y de hartura; las canas como signo de preocupación, la nariz como expresión de superioridad, real o no, son fruto de una experiencia tribal, como charlatanería y charlatanismo encarnados en el sacamuelas son residuo de un estadio cultural ya superado. De más atrás proceden vestigios de prácticas y creencias todavía rastreables: la mala hierba que influye en quien la pisa, la izquierda tenazmente siniestra. Y más allá todavía, afloran ocultas raíces, como la pérfida magia de los números, independientes con frecuencia de su preciso valor aritmético: ¿por qué acicalarse - que pasa de las armas de guerra a la guerra de los sexos- resbala de dos cuadrados perfectos ("tiré à quatre épingles", "de veinticinco alfileres"), que llevan además la justificación del ingrediente que numeran, a un descarnado número primo, que no declara a cuáles

${ }^{47}$ Buena, gentil o linda pieza es, a su vez, remisión a "buena alhaja". No son raras en Ac. estas carambolas: almágama remite a almagameta, almagameta remite a almádana; almádana remite a almádena, y por fin almádena (y su diminutivo almadeneta) explican por fin que se trata de un "mazo de hierro con mango largo, para romper piedras".

${ }^{48}$ Libro IX, xii: "De verbis quae in utramque partem significatione adversa et reciproca dicuntur". 
"trente et un" alude? ¿Por qué el despiadado bordoncillo "un dos, tres, cojito es" traspirenaico corresponde en Guéret "Cin et trois font huit, je n'en rabattrai pas, mélopée méchante qui désig nait le boîteux, en imitant le rythme de sa démarche inégale' (p. 89), maligna melopea que ni siquiera está rimada? ¿Qué sor tilegio esconde la saliva, iniciadora y medicinal, que de los ver: cuetos del narrar pasa a presidir la semejanza física y se olvid de un lado de los montes mientras se perpetúa en otras vertier tes? ¿Existe, ligando las lenguas diferentes de las diferentes tr bus, una lengua de la Babel pre-tribal en cuyo camino la filologí debe ceder el paso, no ya a la etnología ni a la psicología a seca: sino a la pasicología profunda? No parecería improbable que e: temos empezando a vislumbrarlo.

Daniel Devot

Centre National de la Recherche Scientifiqr 